\title{
Interhemispheric gradient of atmospheric radiocarbon reveals natural variability of Southern Ocean winds
}

\author{
K. B. Rodgers ${ }^{1}$, S. E. Mikaloff-Fletcher ${ }^{1,2}$, D. Bianchi ${ }^{1}$, C. Beaulieu ${ }^{1}$, E. D. Galbraith ${ }^{3}$, A. Gnanadesikan ${ }^{4}$, \\ A. G. Hogg ${ }^{5}$, D. Iudicone ${ }^{6}$, B. R. Lintner ${ }^{7}$, T. Naegler ${ }^{8,9}$, P. J. Reimer ${ }^{10}$, J. L. Sarmiento ${ }^{1}$, and R. D. Slater ${ }^{1}$ \\ ${ }^{1}$ AOS Program, Princeton University, Princeton, NJ, USA \\ ${ }^{2}$ National Institute of Water and Atmospheric Research, Wellington, New Zealand \\ ${ }^{3}$ Department of Earth and Planetary Sciences, McGill University, Montreal, QC, Canada \\ ${ }^{4}$ Department of Earth and Planetary Sciences, Johns Hopkins University, Baltimore, MD, USA \\ ${ }^{5}$ Carbon Dating Laboratory, University of Waikato, Hamilton, New Zealand \\ ${ }^{6}$ Stazione Zoologica Anton Dohrn, Naples, Italy \\ ${ }^{7}$ Rutgers, The State University of New Jersey, New Brunswick, NJ, USA \\ ${ }^{8}$ Institute for Environmental Physics, University of Heidelberg, Germany \\ ${ }^{9}$ German Aerospace Center, Institute for Technical Thermodynamics, Department of System Analysis and Technology \\ Assessment, Stuttgart, Germany \\ ${ }^{10}$ Queens University, Belfast, UK
}

Received: 14 January 2011 - Published in Clim. Past Discuss.: 25 January 2011

Revised: 3 August 2011 - Accepted: 4 September 2011 - Published: 26 October 2011

\begin{abstract}
Tree ring $\Delta^{14} \mathrm{C}$ data (Reimer et al., 2004; McCormac et al., 2004) indicate that atmospheric $\Delta{ }^{14} \mathrm{C}$ varied on multi-decadal to centennial timescales, in both hemispheres, over the period between AD 950 and 1830. The Northern and Southern Hemispheric $\Delta^{14} \mathrm{C}$ records display similar variability, but from the data alone is it not clear whether these variations are driven by the production of ${ }^{14} \mathrm{C}$ in the stratosphere (Stuiver and Quay, 1980) or by perturbations to exchanges between carbon reservoirs (Siegenthaler et al., 1980). As the sea-air flux of ${ }^{14} \mathrm{CO}_{2}$ has a clear maximum in the open ocean regions of the Southern Ocean, relatively modest perturbations to the winds over this region drive significant perturbations to the interhemispheric gradient. In this study, model simulations are used to show that Southern Ocean winds are likely a main driver of the observed variability in the interhemispheric gradient over AD 950-1830, and further, that this variability may be larger than the Southern Ocean wind trends that have been reported for recent decades (notably 1980-2004). This interpretation also implies that there may have been a significant weakening of the winds over the Southern Ocean within a few decades of AD 1375, associated with the transition between the Medieval Climate Anomaly
\end{abstract}

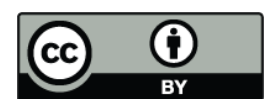

Correspondence to: K. B. Rodgers (krodgers@princeton.edu) and the Little Ice Age. The driving forces that could have produced such a shift in the winds at the Medieval Climate Anomaly to Little Ice Age transition remain unknown. Our process-focused suite of perturbation experiments with models raises the possibility that the current generation of coupled climate and earth system models may underestimate the natural background multi-decadal- to centennial-timescale variations in the winds over the Southern Ocean.

\section{Introduction}

The tree ring $\Delta^{14} \mathrm{C}$ data from INTCAL04 (Reimer et al., 2004) and SHCAL04 (McCormac et al., 2004) indicate that over the period AD 950-1830, atmospheric $\Delta{ }^{14} \mathrm{C}$ varied on multi-decadal to centennial timescales in both hemispheres (the temporal resolution of each record is represented as a sequence of five year means) (Fig. 1a). The earlier part of the record is characterized by an atmosphere that is more depleted in ${ }^{14} \mathrm{CO}_{2}$ (e.g. relatively negative per mil (\%o) values), followed by a change towards an atmosphere more enriched in ${ }^{14} \mathrm{CO}_{2}$ (e.g. relatively positive \%o values) during the 14th century. Although the Northern and Southern Hemispheric records taken together provide evidence of synchronous variations over nearly all timescales, it is difficult

Published by Copernicus Publications on behalf of the European Geosciences Union. 


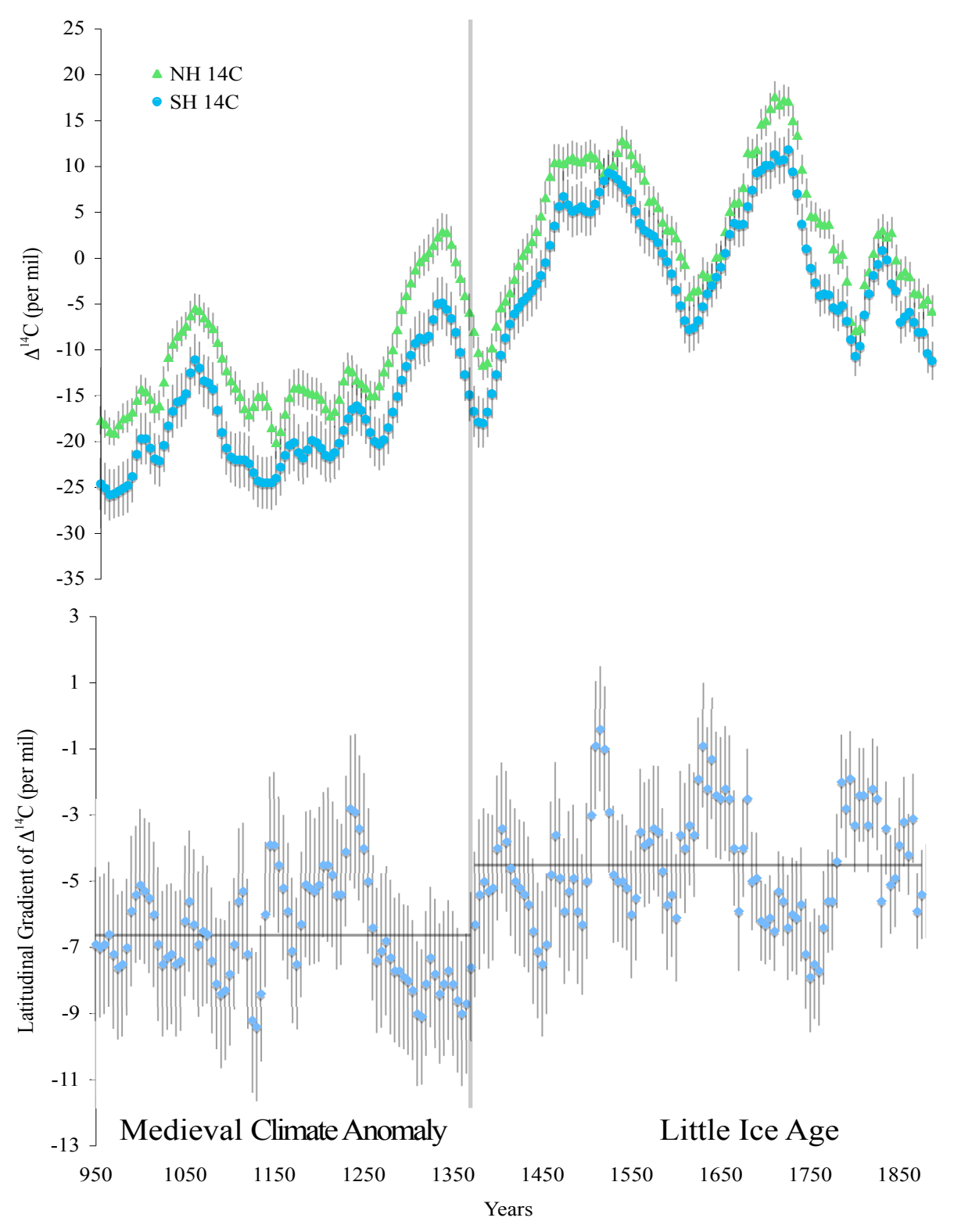

(a)

(b)

Fig. 1. Tree ring measurements of atmospheric $\Delta^{14} \mathrm{C}$ over the period AD 950-1830; (a) the Northern Hemisphere INTCAL04 record (Reimer et al., 2004) is shown as triangles, the Southern Hemisphere SHCAL04 (McCormac et al., 2004) record as circles. The temporal resolution of each record is five years. The uncertainties shown in the panel reflect the uncertainties as given in the INTCAL04 and SHCAL04 datasets themselves. (b) The Interhemispheric Gradient in atmospheric $\Delta^{14} \mathrm{C}$, again with five-year resolution. This is obtained by subtracting the INTCAL04 time series from the SHCAL04 time series. The uncertainties in this difference plot are calculated as the square root of the sum of the squares of the components.

from these data alone to identify the degree to which the variations in $\triangle^{14} \mathrm{C}$ are driven by changes in the production of ${ }^{14} \mathrm{CO}_{2}$ in the upper atmosphere, and the degree to which they are driven by variations in the physical state of the system, and the ensuing perturbations to the partitioning of ${ }^{14} \mathrm{CO}_{2}$ and $\mathrm{CO}_{2}$ (and ${ }^{13} \mathrm{CO}_{2}$ ) between the oceanic, atmospheric, and terrestrial carbon reservoirs.
We calculate the difference between the two highresolution tree-ring-derived hemispheric $\Delta^{14} \mathrm{C}$ reconstructions, shown in Fig. 1a (the Southern Hemisphere SHCAL04 time series minus the Northern Hemisphere INTCAL04 time series), to arrive at a timeseries for the interhemispheric gradient, shown in Fig. 1b. Given that about half of the ${ }^{14} \mathrm{C}$ production occurs in the stratosphere (Masarik and Beer, 1999), it is conceivable that different (and timevarying) stratosphere-troposphere exchange between the two 
hemispheres could contribute to changes in the interhemispheric gradient in the absence of changes in surface fluxes. However, the modeling study of Levin et al. (2009) revealed that the hemispheric asymmetry in stratosphere-troposphere exchange is small, and thus we assume here that changes in the stratospheric source of ${ }^{14} \mathrm{CO}_{2}$ do not project into large gradients in $\Delta^{14} \mathrm{C}$ in the atmospheric boundary layer. It follows from this assumption that changes in the interhemispheric gradient are controlled by surface fluxes.

The interhemispheric gradient has persistent negative values, reflecting the fact that the Southern Hemisphere $\Delta^{14} \mathrm{C}$ tends to be lower than it is in the Northern Hemisphere (Fig. 1b). Analysis reveals that this time series contains red noise, with variability in evidence on all timescales. We conducted a change point analysis test of the timeseries following Worsley (1979), which identified a statistically significant (>99\% confidence level) shift in 1375 in agreement with Turney and Palmer (2007). This point marks a change between a mean interhemispheric gradient of $-6.63 \%$ o for the earlier part of the record and $-4.48 \%$ o for the later part of the record, implying a change in surface fluxes of radiocarbon.

How are these changes in atmospheric $\Delta^{14} \mathrm{C}$ linked to variations in the Earth's climate? Before postulating a mechanism, it is instructive to first consider the earth system modeling study of the last millenium presented by Jungclaus et al. (2010). They conducted a series of ensemble calculations to understand climate and $\mathrm{CO}_{2}$ variability. Their modeling configuration allows for separate contributions to atmospheric $\mathrm{CO}_{2}$ variations from natural variability, solar variability, and volcanic activity. An important finding of their study is that their state-of-the-art earth system model underrepresents the amplitude of atmospheric $\mathrm{CO}_{2}$ variability over the last millenium. This points to the potential existence of missing mechanisms in their earth system model.

Here our goal is to test the hypothesis that over the last millennium, multi-decadal to centennial-timescale variability in Southern Ocean winds was larger than what is typically represented in coupled climate models. If this is true, it may help to account for the "missing mechanism" that caused the earth system model of Jungclaus et al. (2010) to underestimate variability in atmospheric $\mathrm{CO}_{2}$ concentrations over the last millenium (Etheridge et al., 1996). We wish to test this hypothesis by presenting and developing $\Delta^{14} \mathrm{C}$ as a tracer of variations in the winds over the Southern Ocean. More generally, we wish to introduce and develop the idea that atmospheric latitudinal gradients in $\Delta^{14} \mathrm{C}$ could provide a tracer that integrates wind variations over large spatial scales over the Southern Ocean, with this tracer thus not suffering from the representativeness errors described by Wunsch (2010) for a number of paleo-proxy tracers.

The study of Turney and Palmer (2007) has previously interpreted the interhemispheric gradient in atmospheric $\Delta^{14} \mathrm{C}$ as being a tracer of past variations in equatorial Pacific seaair exchanges of ${ }^{14} \mathrm{CO}_{2}$ and $\mathrm{CO}_{2}$. They considered the structure of the interhemispheric gradient changes shown in Fig. $1 \mathrm{~b}$ and argued that there was a significant change associated with the transition between the Medieval Climate Anomaly and the Little Ice Age during the 14th century, which they attributed to changes in ENSO. That was in part motivated by the analysis of $\Delta^{14} \mathrm{C}$ as a tracer of the Peru Upwelling by Toggweiler et al. (1991), as well as by the studies of Feely et al. (1999), Le Quéré et al. (2000), and Obata and Kitamura (2003) that demonstrated that the Equatorial Pacific was the largest region of interannual variability in seaair $\mathrm{CO}_{2}$ fluxes for the global mean.

Our intention here is not to challenge the equatorial mechanism set forth by Turney and Palmer (2007). Rather, our goal is to show that the Southern Ocean is making a firstorder contribution to the time-varying component of the interhemispheric gradient signal in $\Delta^{14} \mathrm{C}$. More specifically, we wish to establish that changes of the interhemispheric gradient, such as the change identified at 1375 , most likely reflect past changes of the integrated strength of the winds over the Southern Ocean. This is done through the use of somewhat idealized process perturbation experiments with models. The model configuration chosen for this study is intended to facilitate a "test of concept" that focuses on perturbations over the Southern Ocean. Although our focus is the last millenium, we are more generally interested in the sensitivity of the Southern Ocean to perturbations over a wide range of timescales.

We are also interested in connecting the results of our study over the last millenium to mechanisms that have been presented in other context for rapid global changes in response to perturbations to Northern Hemisphere temperatures. Specifically, we are interested in the mechanism that was originally presented by Anderson et al. (2009) and then further developed and tested in a modeling framework by Lee et al. (2011) for deglaciation and millenial-timescale variations in the climate system. In those studies, the idea was explored that an abrupt change towards cooler conditions in the Northern Hemisphere can drive an abrupt southward excursion of the Intertropical Convergence Zone (ITCZ), and this subsequently can drive increases in the surface winds over the Southern Ocean. This atmospheric teleconnection mechanism is distinct from the type of ocean-focused set of connections that have previously been invoked to account for the way in which changes in the North Atlantic may impact the Southern Ocean. More generally one can raise the question of whether a cooling in the northern extratropics at the Little Ice Age onset could have driven a southwards excursion of the ITCZ, and a corresponding increase in the winds over the Southern Ocean. It is our hope that $\Delta^{14} \mathrm{C}$ as a climate dynamical tracer can shed light upon this mechanism. 


\section{Model configuration}

In order to understand the processes that drive interhemispheric gradients in $\Delta^{14} \mathrm{C}$, we have chosen to use a modeling configuration that consists of an ocean general circulation model and an atmospheric transport model that are run sequentially rather than interactively or coupled. This allows full control over the way the Southern Ocean winds are perturbed. The ocean model is first run to steady state for its ocean interior $\Delta^{14} \mathrm{C}$ distribution. Both DIC and $\mathrm{DI}^{14} \mathrm{C}$ concentrations are set initially to $2000 \mu \mathrm{mol} \mathrm{kg}^{-1}$, where the $\mathrm{DI}^{14} \mathrm{C}$ concentrations have been multiplied by a scaling factor corresponding to the ratio of $\mathrm{CO}_{2}$ to ${ }^{14} \mathrm{CO}_{2}$ in pre-anthropogenic atmosphere (see Appendix A for more details). For DIC, convergence with the spinup is tested by the constraint that globally integrated sea-air $\mathrm{CO}_{2}$ fluxes must be less than $0.01 \mathrm{Pg} \mathrm{Cyr}^{-1}$. For $\Delta^{14} \mathrm{C}$, the convergence test is that $98 \%$ of the ocean interior volume should have drift of less than $0.001 \%$ o per year (Aumont, 1998). This is then followed by the idealized ocean perturbation studies, with the perturbation consisting of scalar multiplication of the strength of the winds over the Southern Ocean.

The atmospheric transport model is run using sea-air fluxes of ${ }^{14} \mathrm{CO}_{2}$ and $\mathrm{CO}_{2}$ from the ocean model experiments as its lower boundary conditions. The tracers ${ }^{14} \mathrm{CO}_{2}$ and $\mathrm{CO}_{2}$ are advected and mixed in the atmospheric transport model, and the sources and sinks are described below. In the perturbation studies here, there is an inherent inconsistency in that the wind stress perturbations used with the ocean model are not contained in the atmospheric transport fields used for the transport model, since each perturbation experiment uses identical atmospheric circulation and mixing. In a separate paper, we are evaluating the role of variability in atmospheric transport, and there we will interpret that variability for improved science understanding of the impact of ITCZ variations.

\subsection{Ocean model}

The ocean code used here is Version 3 of the GFDL Modular Ocean Model (MOM3) (Pacanowski and Griffies, 1999). The model, which has $4^{\circ}$ horizontal resolution and 24 vertical levels, is forced at the surface with buoyancy fluxes from the climatology of da Silva et al. (1994), corrected as described in Gnanadesikan et al. (2004). Temperature is restored to observations with a timescale of 30 days over the $25 \mathrm{~m}$-thick surface layer while salinity is restored to surface observations with a 120 day time scale at all points except for four coastal points around the Antarctic where subsurface salinity values and a 30 day restoring are used to ensure formation of the proper water masses during the winter. Wind stress is taken from the ECMWF climatology (Trenberth et al., 1989). The control model corresponds to the P2A model of Gnanadesikan et al. (2004).
The representation of $\Delta^{14} \mathrm{C}$ in the model follows the OCMIP-2 ABIOTIC protocol (http://www.ipsl.jussieu.fr/ OCMIP/phase2/), using the gas exchange parameterization of Wanninkhof (1992). The atmospheric $\Delta{ }^{14} \mathrm{C}$ is maintained at $0 \%$ or all experiments presented here, and the atmospheric $\mathrm{CO}_{2}$ concentration is maintained at $278 \mu \mathrm{atm}$. A caveat with the ABIOTIC OCMIP-2 representation of $\Delta^{14} \mathrm{C}$ is that ${ }^{13} \mathrm{C}$ is ignored, despite the fact that it can play a nonnegligible role in determining $\Delta^{14} \mathrm{C}$ (see Appendix $\mathrm{A}$ for a more detailed description of $\Delta^{14} \mathrm{C}$ as a tracer).

Surface wind stresses $\tau$ are calculated using a quadratic bulk formula:

$\tau \rho C_{\mathrm{d}} \boldsymbol{u}|\boldsymbol{u}|$

where $\rho$ is the density of air, $C_{\mathrm{d}}$ is a dimensionless drag coefficient, and $\boldsymbol{u}$ is the horizontal surface wind vector at $10 \mathrm{~m}$. Likewise gas exchange is calculated using the formula from Wanninkhof (1992):

$k_{\mathrm{av}}=0.337\left|\boldsymbol{u}_{\mathrm{av}}\right|^{2}(S c / 660)^{0.5}$

where $k_{\mathrm{av}}$ is the piston velocity, Sc is the Schmidt number, and $\boldsymbol{u}$ is the horizontal surface wind vector at $10 \mathrm{~m}$. In fact Wanninkhof (1992) had specified 0.39 for the coefficient on the right hand side, and 0.337 is the coefficient for the right hand side chosen for the OCMIP-2 protocol. It is known that the Wanninkhof (1992) parameterization suffers from a number of limitations that have been described in Krakauer et al. (2006), Naegler et al. (2006), Sweeney et al. (2007), and Naegler (2009). Although the value we have chosen to use here $(0.337)$ is $14 \%$ smaller than the value proposed by Wanninkhof (1992) (0.39), we have initiated a new independent study to investigate the sensitivity of the disequilibrium flux to the choice of gas exchange parameterization.

\subsection{Atmospheric transport model}

The atmospheric transport model Tracer Model 3 Version 3 (Heimann and Körner, 2003) was used for this study. This is a three-dimensional Eulerian model driven by offline wind fields. Here we have used both a coarse grid resolution $\left(7.8^{\circ}\right.$ latitude by $10^{\circ}$ longitude with nine vertical levels) and a fine grid resolution $\left(4.4^{\circ}\right.$ latitude by $5^{\circ}$ longitude with 19 vertical levels) version of the model in order to get a lower level estimate of the uncertainty associated with errors in the atmospheric transport model following Rödenbeck et al. (2008). The fine grid resolution has been shown to be substantially less diffusive in simulations of point sources, radon, and $\mathrm{SF}_{6}$ (Heimann and Körner, 2003).

The wind fields used for the experiments here were taken from the NCEP reanalysis (Kalnay et al., 1996). The 6-h mean reanalysis fluxes were used, and interpolated to the time step of the transport model. Six different simulations were run with the atmospheric transport model using repeating wind fields from 1995 to 2000 , with the six different $20 \mathrm{yr}$ simulations performed by looping repeatedly over one 
of each of the $6 \mathrm{yr}$ spanning 1995 and 2000. The method we have used, namely of looping through an eleven year stretch of reanalysis forcing, is commonly used in atmospheric modeling studies, for example in the studies of Battle et al. (2006) and Naegler et al. (2007). The resulting tracer distributions from the six model runs were averaged to create a climatological field. By averaging over multiple years, we are in fact removing variability in the Intertropical Convergence Zone.

Five different flux processes were prescribed in the model: sea-air fluxes of $\mathrm{CO}_{2}$, sea-air fluxes of ${ }^{14} \mathrm{CO}_{2}$, stratospheric production of ${ }^{14} \mathrm{C}$, terrestrial disequilibrium of ${ }^{14} \mathrm{C}$, and a neutral terrestrial biosphere for $\mathrm{CO}_{2}$ [The neutral biosphere is calculated by removing the annual mean terrestrial flux from each grid box in the model, in order to represent the seasonal rectification of atmospheric $\mathrm{CO}_{2}$ (Randerson et al., 1997; Gurney et al., 2000)]. Each was treated as a separate tracer, and all five are combined to calculate atmospheric gradients of $\Delta^{14} \mathrm{C}$. Sea-air fluxes of $\mathrm{CO}_{2}$ and ${ }^{14} \mathrm{CO}_{2}$ are taken directly from the ocean model output. In addition, we included a source in the mid-to-upper stratosphere due to production by cosmogenic radiation, adapted from the source function of Turnbull et al. (2009). The magnitude of the atmospheric source was tuned such that it was consistent with sea-air fluxes of ${ }^{14} \mathrm{CO}_{2}$ from the ocean model.

Finally, we included a disequilibrium sink due to the residence time of carbon in the terrestrial biosphere. While the terrestrial biosphere is known to have a substantial disequilibrium in modern times due to the transient effect of bomb-generated ${ }^{14} \mathrm{CO}_{2}$, for the pre-anthropogenic period the pre-industrial disequilibrium is thought to have been small, as the residence time of $\mathrm{CO}_{2}$ in the terrestrial biosphere is short relative to its radioactive decay timescale (Siegenthaler, 1986). A simple estimate based on the lifetime of ${ }^{14} \mathrm{C}$ in the biosphere and the mass of the biosphere suggests that the pre-anthropogenic terrestrial disequilibrium must be no more than $7 \%$ of the oceanic disequilibrium.

We therefore formulated a simple representation of the terrestrial biospheric disequilibrium flux by calculating the global total terrestrial disequilibrium as $7 \%$ of the ocean value and distributed it spatially according to the absolute value of net ecosystem productivity (NEP) of the Carnegie Ames Stanford Approach (CASA) neutral biosphere (Randerson et al., 1997). We calculate the flux as follows: according to the IPCC AR4 assessment, the terrestrial biomass was $2300 \mathrm{PgC}$, and the carbon mass in the ocean was $38000 \mathrm{PgC}$. If one assumes that the average $\Delta^{14} \mathrm{C}$ of the terrestrial biosphere was close to $\Delta^{14} \mathrm{C}=0 \%$ (normalized ${ }^{14} \mathrm{C}$ activity $=1$ ) (at an average age of $30 \mathrm{yr}$ ), and if one assumes an average oceanic value of $\Delta{ }^{14} \mathrm{C}=-150 \%$ (normalized ${ }^{14} \mathrm{C}$ activity $=0.85$ ), then given that the fluxes from the atmosphere to these reservoirs must supply the radioactive decay, the ratio of natural radiocarbon fluxes into the ocean relative to the terrestrial biosphere is $(38000 \times 0.85) / 2300=14$. By inverting this factor, we get $1 / 14=7 \%$.
The CASA neutral biosphere was used to simulate seasonal rectification in $\mathrm{CO}_{2}$ and ${ }^{14} \mathrm{CO}_{2}$, although this effect is relatively negligible for $\Delta{ }^{14} \mathrm{C}$. The radioactive decay of ${ }^{14} \mathrm{C}$ in the atmosphere was neglected because the decay-time of ${ }^{14} \mathrm{C}$ is very long relative to the duration of the simulations, and the magnitude of the signal is roughly equivalent in both hemispheres. Thus ignoring decay in the atmosphere will have a negligible impact on the results of the sensitivity study considered here.

\subsection{Coupling of ocean and atmosphere models}

The atmospheric transport model is used together with the ocean model to explore the sensitivity of the interhemispheric gradient to idealized wind perturbations over the Southern Ocean. This sensitivity was evaluated by perturbing the P2A configuration of the ocean model through a scalar multiplication of the wind stress (used for dynamics) and wind speed (used for tracer gas exchange) over the entire region south of $30^{\circ} \mathrm{S}$. This test was motivated by the fact that surface atmospheric wind perturbations can impact oceanic $\Delta^{14} \mathrm{C}$ both through changes to the physical state of the ocean in the absence of changes in gas exchange, as well as changes in gas exchange in the absence of perturbations to the physical state of the ocean. Of course the two types of perturbations in general will not be completely independent, but nevertheless this sensitivity is important to test for a mechanistic interpretation. This idealized perturbation is analogous to that used with the same ocean model in the previous study of Mignone et al. (2006) (although there the perturbation was applied only to the wind stress but not in the gas exchange formulation). The perturbation here is applied to the amplitude but not the structure of the winds over the Southern Ocean. The idealized perturbations with the ocean model were applied over a period of $20 \mathrm{yr}$. This timescale is chosen given our interest in decadal timescale perturbations, and independent convergence tests indicate that the perturbations obtained for years 11-20 are generally representative of longer multi-decadal timescales. The monthly sea-air fluxes of $\mathrm{CO}_{2}$ and ${ }^{14} \mathrm{CO}_{2}$ from the ocean model over years $11-20$ were used as the lower boundary condition for the Atmospheric Transport Model experiments. This is done for 10 separate cases, for perturbations spanning wind multiplicative factors of 0.6 to 1.5 in intervals of 0.1 .

\section{Results}

We begin by looking at the annual mean sea-air flux for $\mathrm{CO}_{2}$ (Fig. 2a) and ${ }^{14} \mathrm{CO}_{2}$ (Fig. 2b) for the model. The seaair flux of ${ }^{14} \mathrm{CO}_{2}$ has been scaled by a multiplicative factor $\left(0.85 \times 10^{12}\right)$ as a means of normalizing the flux to the pre-anthropogenic late 19th century atmospheric value of 
(a)

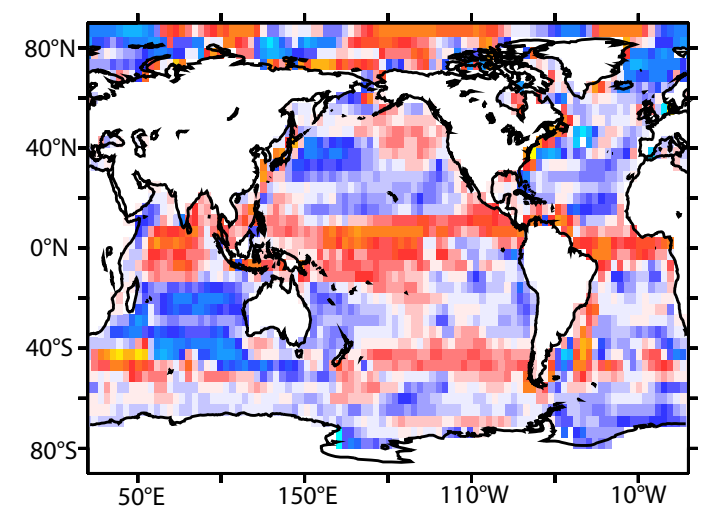

(c)

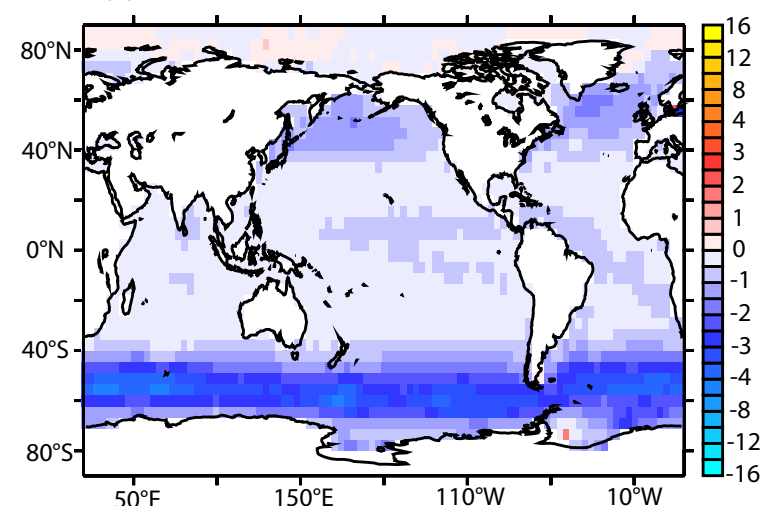

(b)
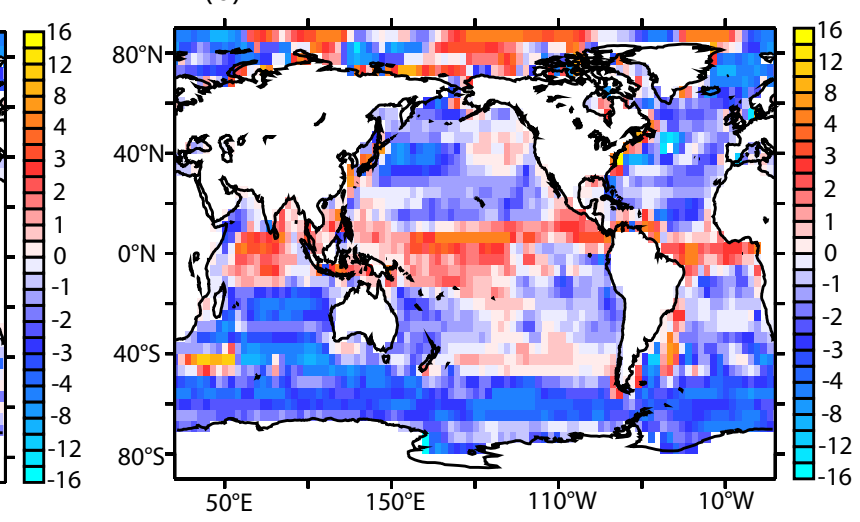

(d)

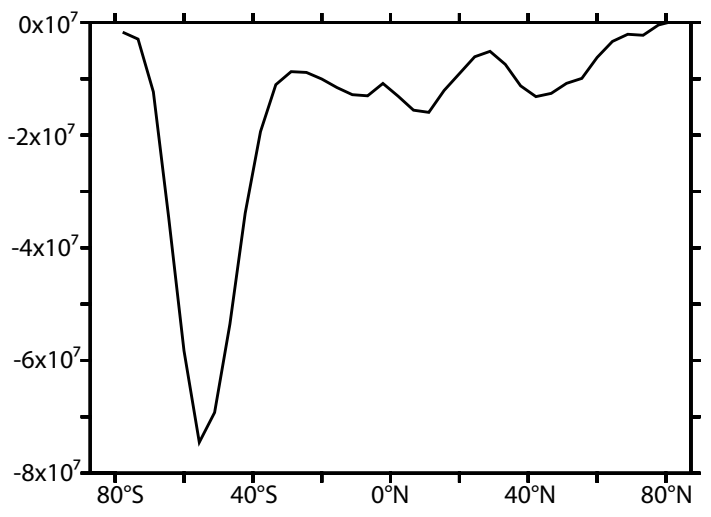

Fig. 2. Surface annual mean sea-air tracer fluxes from the mean state of the MOM3 ocean model. (a) $\mathrm{CO}_{2}$ flux $\left(\mathrm{mol} \mathrm{C} \mathrm{m}^{-2} \mathrm{~s}^{-1}\right)$. (b) ${ }^{14} \mathrm{CO}_{2}$ flux (scaled via multiplication by the late 19 th century ratio of ${ }^{12} \mathrm{CO}_{2} /{ }^{14} \mathrm{CO}_{2}$, or $\Delta^{14} \mathrm{C}=0$, in the atmosphere) $\left(\mathrm{mol} \mathrm{Cm}^{-2} \mathrm{~s}^{-1}\right)$. (c) disequilibrium flux $\phi_{\text {diseq }}\left[{ }^{14} \mathrm{CO}_{2}\right.$ flux (scaled) minus $\mathrm{CO}_{2}$ flux $]\left(\mathrm{mol} \mathrm{m}^{-2} \mathrm{~s}^{-1}\right)$. (d) Zonal integral of the disequilibrium flux $\left[\phi_{\text {diseq }}\right]$ $\left(\mathrm{molC} \mathrm{m}{ }^{-1} \mathrm{~s}^{-1}\right)$.

$\Delta^{14} \mathrm{C}=0 \%$. This scaling allows us to define the disequilibrium flux $\phi_{\text {diseq }}$ :

$\phi_{\text {diseq }}=\phi_{14} \mathrm{C}^{12 / 14}-\phi_{12} \mathrm{C}$

where $\phi_{14} \mathrm{C}$ is the sea-air flux of ${ }^{14} \mathrm{CO}_{2}, r^{12 / 14}$ is the prebomb atmospheric ${ }^{12} \mathrm{C} /{ }^{14} \mathrm{C}$ ratio, and $\phi_{12} \mathrm{C}$ is the sea-air flux of $\mathrm{CO}_{2}$. Henceforth, the units for $\phi_{\text {diseq }}$ will be expressed in terms of Gigatons of Modern Carbon Equivalent (GtMCE). Conveniently, this scaling is precisely that specified by the OCMIP-2 protocol for modeling $\Delta{ }^{14} \mathrm{C}$, with that choice for OCMIP-2 being motivated by numerical considerations. Thus the product in the first term on the right hand side of the above equation corresponds precisely to what is represented in the model for ${ }^{14} \mathrm{CO}_{2}$ fluxes, and thereby $\phi_{\text {diseq }}$ in the model is calculated through a simple difference between ${ }^{14} \mathrm{CO}_{2}$ and $\mathrm{CO}_{2}$ fluxes.

The annual mean distribution of $\phi_{\text {diseq }}$ is shown in Fig. 2c. Negative (blue) values indicate a tendency for the flux of ${ }^{14} \mathrm{CO}_{2}$ into the ocean to be larger than the flux of $\mathrm{CO}_{2}$, thereby driving the atmospheric $\Delta^{14} \mathrm{C}$ towards negative values from the pre-anthropogenic steady state of $\Delta^{14} \mathrm{C}=0$. The model has a negative global mean $\phi_{\text {diseq }}$ values due to the fact that ${ }^{14} \mathrm{C}$ is produced by spallation in the upper atmosphere, and transferred across the sea-air boundary to balance the decay of $\mathrm{DI}^{14} \mathrm{C}$ in the ocean interior. (As noted above, this study will also account for the $7 \%$ contribution of the terrestrial biosphere to the global $\left.\phi_{\text {diseq }}\right)$.

The zonal integral of $\phi_{\text {diseq }}$ is shown in Fig. $2 d$. This nomenclature is chosen so as to be clear about the fact that ${ }^{14} \mathrm{CO}_{2}$ fluxes are not the same as $\mathrm{CO}_{2}$ fluxes. The total $\phi_{\text {diseq }}$ into the ocean is $3.6 \mathrm{GtMCE} \mathrm{yr}^{-1}$, with $74 \%$ occurring in the Southern Hemisphere and $62 \%$ south

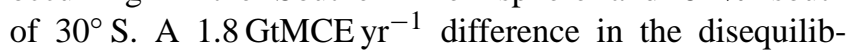
rium flux between the Northern and Southern Hemispheres would be expected to produce an interhemispheric flux of

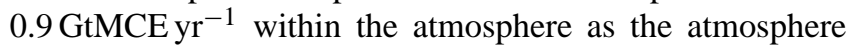
came into equilibrium. Given an interhemispheric exchange time of order $1.3 \mathrm{yr}$ (Geller et al., 1997) this would imply a 1.17 GtMCE interhemispheric difference in the atmospheric radiocarbon inventory. Given a preindustrial tropospheric carbon inventory of $\sim 480 \mathrm{GtC}-$ or $240 \mathrm{GtC} /$ hemisphere, this would correspond to a difference of $4.9 \%$. This value 
is within $20 \%$ of the mean interhemispheric gradient seen in Fig. 1b. This mass balance calculation illustrates how the $\phi_{\text {diseq }}$ at the sea surface is the fundamental driver of the interhemispheric gradient.

This simple scaling argument is more rigorously confirmed using the atmospheric transport model. For the P2A simulation performed with the MOM3 model, a corresponding simulation was performed with the atmospheric transport model using the sea-air fluxes of $\mathrm{CO}_{2}$ from the ocean model over a period of $10 \mathrm{yr}$. The $10 \mathrm{yr}$ of the simulation was deemed to be appropriate as the interhemispheric gradient converges in less than two years. Although the amplitude of the interhemispheric gradient converges quickly, we are specifically interested in the multi-decadal (and longer) timescale variations revealed in Fig. 1b. Therefore, we also consider other sources and sinks of ${ }^{14} \mathrm{CO}_{2}$ in the Earth system, including the production of ${ }^{14} \mathrm{CO}_{2}$ in the upper atmosphere and fluxes between the atmosphere and the terrestrial biosphere. The mean meridional structure of $\Delta^{14} \mathrm{C}$ in the atmospheric boundary layer is shown in Fig. 3 (black curve). The $\Delta^{14} \mathrm{C}$ activity is shown as a deviation from the value at the North Pole in order to emphasize the amplitude and structure of the meridional gradient. Additionally the large-scale meridional structure is controlled by the ocean fluxes. The resulting model shows a difference of about $3 \%$ o between the mid-latitude Northern and Southern Hemispheres. This is smaller than the observed gradient of $6.63 \%$ for the earlier part of the record and $4.48 \%$ for the later part of the record, and is also smaller than the gradient estimated from the simple scaling arguments. This suggests that the atmospheric transport model may be overestimating interhemispheric exchange.

The tendency for a global maximum in the absolute value of $\phi_{\text {diseq }}$ over the Southern Ocean is the result of two factors. The first is that the Southern Ocean is where the most depleted waters come to the surface, as illustrated in Fig. 4a using the pre-bomb data product for $\Delta^{14} \mathrm{C}$ from GLODAP (Key et al., 2004, following the method developed and presented by Rubin and Key, 2002) along a continuous track running from the North Atlantic to the Southern Ocean to the North Pacific. Surface waters in the Southern Ocean are poorly equilibrated, with values of $-120 \%$, while North Atlantic waters are closer to $-50 \%$, and thereby the average flux to the ocean is more than twice as large per unit area over the Southern Ocean. Our model (Fig. 4b) captures this pattern of $\Delta^{14} \mathrm{C}$ activities relatively well. Additionally, the larger areal extent of the Southern Ocean means that this larger flux (per unit area) produces a significantly larger integrated uptake of ${ }^{14} \mathrm{CO}_{2}$ than the North Atlantic.

Next we consider the distribution of $\Delta^{14} \mathrm{C}$ in the atmospheric transport model, with the fluxes taken from the perturbation experiments with the ocean model used as a lower boundary condition. The interhemispheric gradient (the deviation of the zonal mean surface atmospheric activities from the $\Delta^{14} \mathrm{C}$ activity at the North Pole) is shown in Fig. 5a for

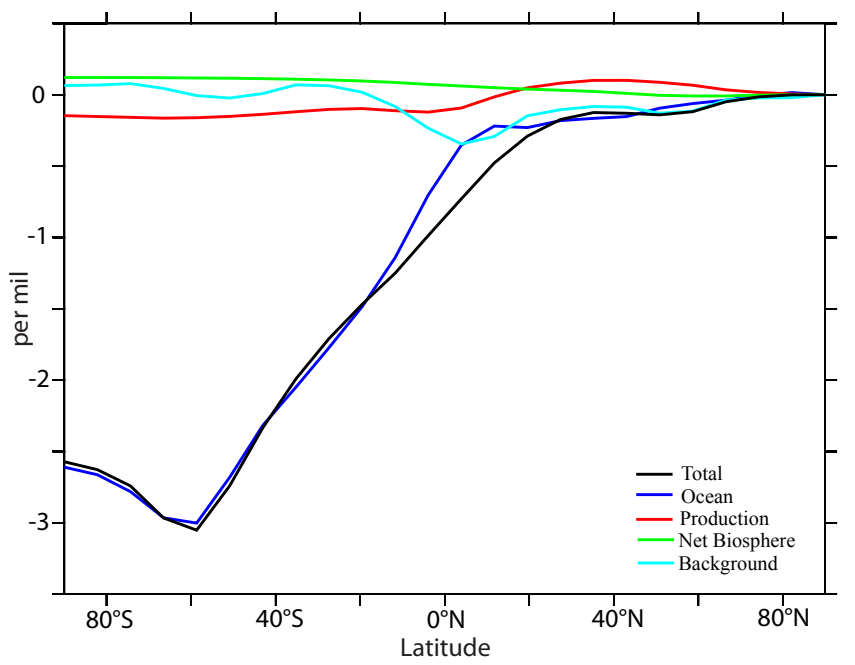

Fig. 3. The mean meridional structure of $\Delta^{14} \mathrm{C}$ in the atmospheric boundary layer of the atmospheric transport model under steady-state cyclostationary conditions, shown as deviations from the $\Delta^{14} \mathrm{C}$ activity simulated at the North Pole. Shown are the total structure of the interhemispheric gradient (black), the component due to sea-air fluxes of $\mathrm{CO}_{2}$ and ${ }^{14} \mathrm{CO}_{2}$ (blue), the component due to spallation/production of ${ }^{14} \mathrm{CO}_{2}$ in the atmosphere (red) and the component due to the net biosphere disequilibrium (green). (per mil). The $\Delta^{14} \mathrm{C}$ for each of these components is calculated as the ${ }^{14} \mathrm{CO}_{2}$ from the specific process being considered and the total $\mathrm{CO}_{2}$ from all processes. The background component reflects a globally uniform initial value of ${ }^{14} \mathrm{C}$ plus the seasonal rectification in ${ }^{14} \mathrm{C}$ for the terrestrial biosphere described in Sect. 2.2, divided by the spatially varying $\mathrm{CO}_{2}$ from all processes. This background value is necessary in order to ensure that the other curves sum to the black curve.

the case where the scalar perturbation to the winds has been applied to both the wind stress (used for dynamical forcing) and the surface wind speed (used for gas exchange).

Figure 5a reveals a clear response in the interhemispheric gradient to the strength of the winds over the Southern Ocean, with a larger interhemispheric gradient corresponding to stronger winds. Here we use the notation $\mathrm{p} 2 \mathrm{a}_{-} 0.5$ to represent the response of the $\mathrm{P} 2 \mathrm{~A}$ ocean model to a 0.5 multiplicative perturbation, p2a_0.6 for the case of a 0.6 multiplicative perturbation and so on. In this way, the $\mathrm{p} 2 \mathrm{a}_{-} 1.0$ run corresponds to the case with unperturbed winds. Whereas the interhemispheric gradient is nearly $3 \%$ at $55^{\circ} \mathrm{S}$ for the control case (p2a_1.0), it is in excess of $6.0 \%$ for the p2a_1.4 case. For the p2a_1.0 case, we note here that the mean simulated gradient is smaller (by $35 \%$ ) than what is found in the data for the mean (Fig. 1b), which had a mean of greater than 5\%o over the period AD 950-1830, and it is also smaller than what is found with the scaling argument presented in Sect. 2. A number of factors are expected contribute to the under-estimation of the interhemispheric gradient in the model simulation, including numerical diffusion in the 
(a)

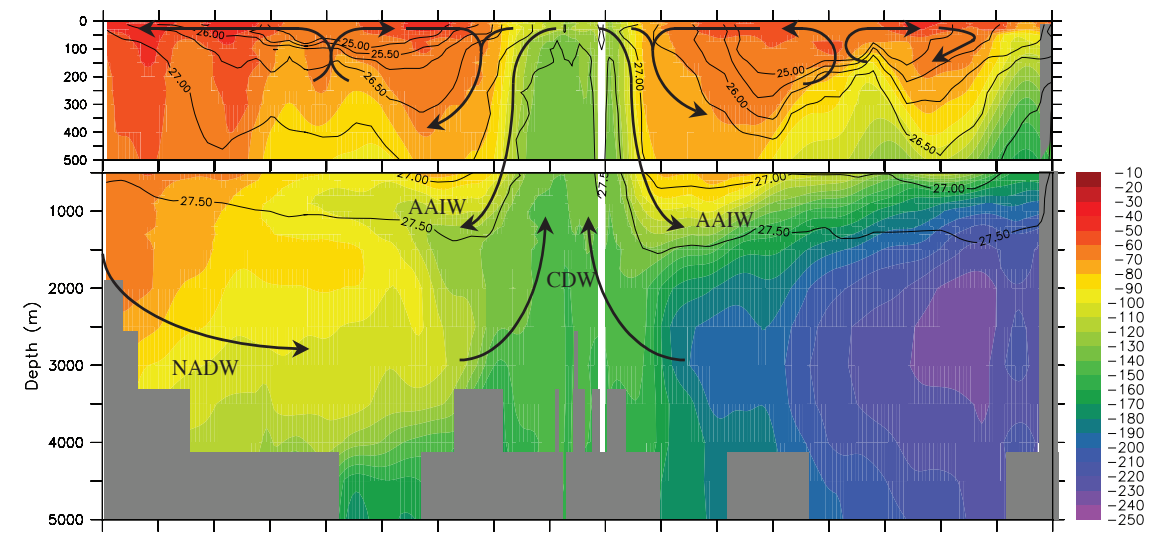

(b)

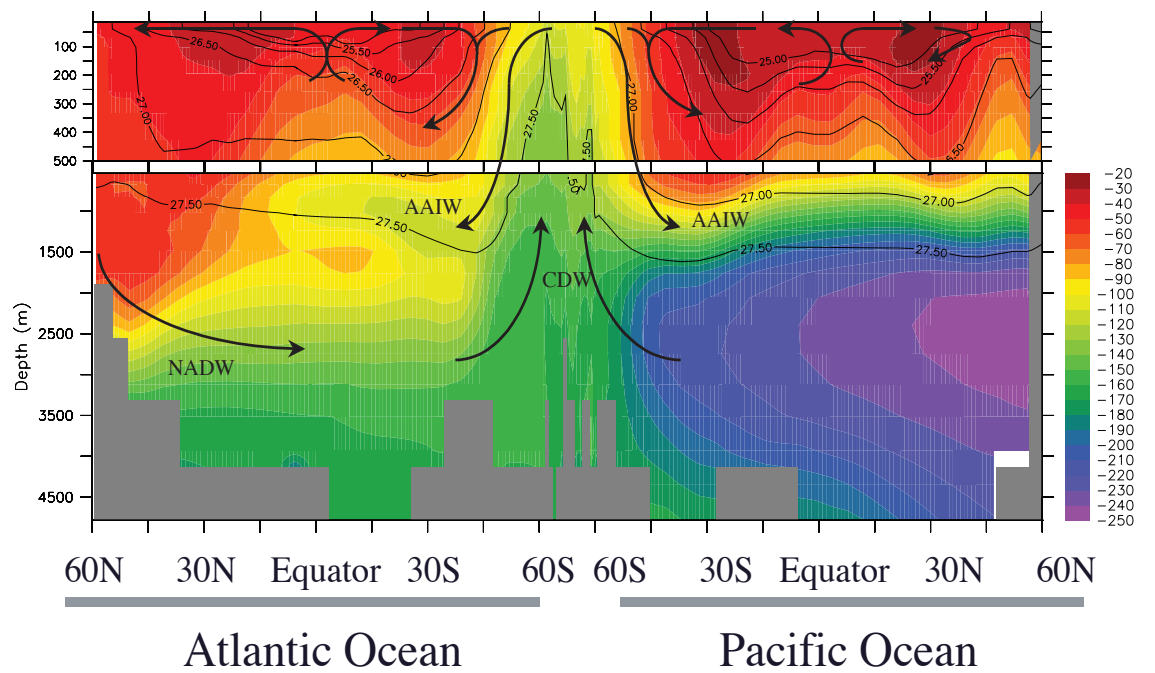

Fig. 4. Southern Ocean-centric view of pre-bomb $\Delta^{14} \mathrm{C}$ in the ocean interior (per mil). (a) GLODAP (Key et al., 2004). (b) MOM3 P2A (Gnanadesikan et al., 2004).

atmospheric transport model and biases in in the atmospheric transport fields themselves. For this reason the disagreement between the mean interhemispheric gradient between Fig. 1b (measurements) and Fig. 4a (p2a_1.0 simulation) is within the range of uncertainty with such models.

In order to evaluate whether the simulated interhemispheric gradient shown in Fig. 5a is controlled primarily by the wind stress (which directly impacts the ocean circulation through the momentum equations) or the wind speed (which only acts on tracers through the gas exchange parameterization), we conducted two additional sets of perturbation studies with the ocean model (Fig. 5b, c). The information shown in Fig. 5a-c is reconsidered in a scatterplot in Fig. 6 for the case of the difference in the mean $\Delta^{14} \mathrm{C}$ north of $30^{\circ} \mathrm{S}$ and the mean $\Delta^{14} \mathrm{C}$ south of $30^{\circ} \mathrm{S}$. The green triangles represent the full signal, the red squares represent the sensitivity to windspeed perturbations, and blue diamonds represent the sensitivity to windstress perturbations.
The dependence of gas exchange rates on windspeed dominates over the effect of wind stress on ocean circulation. When both effects are included, perturbations of slightly larger than $20 \%$ in the windspeed produce changes in the interhemispheric gradient of order $1.6 \%$ over the interval of two decades. Given our prior assumptions, this suggests that natural variability of Southern Ocean winds over the past millenium have been of order $20 \%$.

To put such variability in context, we compare it to the trend in Southern Ocean winds that is widely interpreted as being an anthropogenic perturbation over 1980-2004 (the period of focus of the study of Le Quére et al., 2007). Here we focus on the surface winds in the NCEP-1 reanalysis (Kalnay et al., 1996) that served as the forcing for the ocean modeling component of the study of Le Quéré et al. (2007). The time-mean 10 meter windspeeds over 1949-2008 are shown in Fig. 7a, and the monthly average of the windspeeds over the latitude band $40^{\circ} \mathrm{S}-60^{\circ} \mathrm{S}$ are shown in Fig. $7 \mathrm{~b}$. Over the 

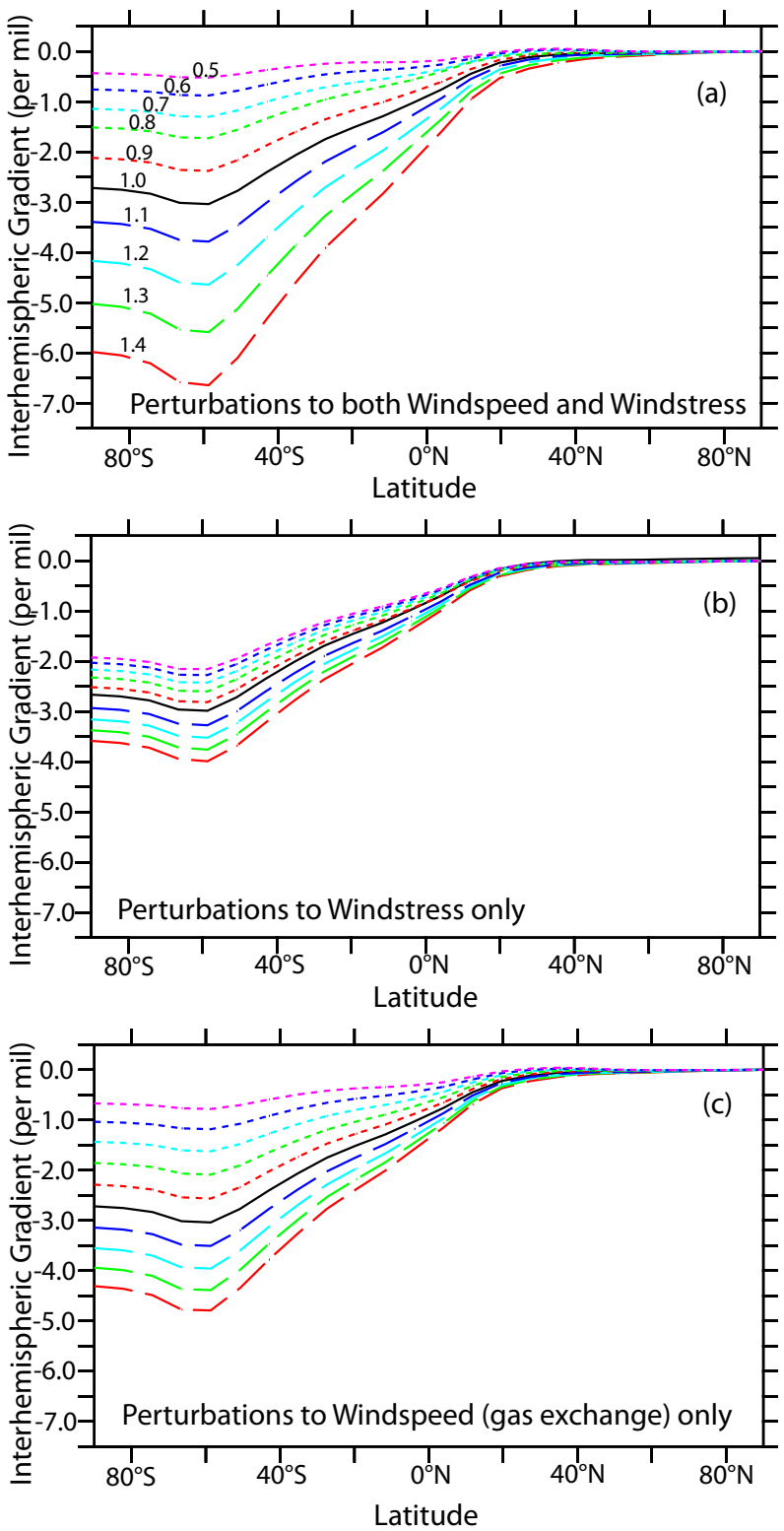

Fig. 5. Response of zonal surface $\Delta^{14} \mathrm{C}$ to Southern Ocean wind perturbations (per mil deviations from value at North Pole for each case). (a) Perturbation applied to both wind stress (dynamical forcing) and wind speed (gas exchange). (b) Perturbation applied to wind stress (but not gas exchange). (c) Perturbation applied to gas exchange (but not wind stress).

period 1980-2004, a linear trend analysis indicates a rate of increase in wind strength corresponding to a $10 \%$ increase over that interval. This observed change over $2-1 / 2$ decades is in fact less than what were inferred here to be the natural background variability of the surface wind strength over decadal timescales over the Southern Ocean from Fig. 6. There is a wide consensus that a significant part of the trend over 1980-2004 can be attributed to the effects of ozone and climate. What we wish to emphasize here is that the nat-

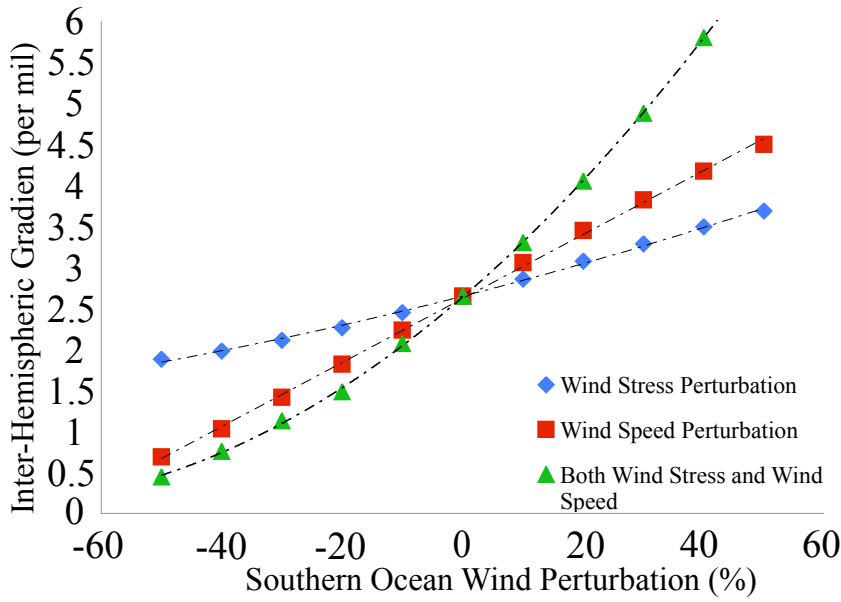

Fig. 6. Scatterplot of response of the interhemispheric gradient of atmospheric $\Delta^{14} \mathrm{C}$ to surface windspeed perturbations after $20 \mathrm{yr}$.

ural variability over the pre-anthropogenic period may have been at least as large as the anthropogenic trend detected over recent decades.

\section{Discussion}

There are two main results in this study. The first is that the trend towards increased windspeeds over the Southern Ocean over recent decades (in particular over the period 1980-2004 emphasized by Le Quéré et al., 2007) may be of the same amplitude as the natural background variability over decadalto-multi-decadal timescales for the interval AD 950-1830. These long INTCAL04 and SHCAL04 records account for multiple realizations of multi-decadal to centennial timescale variations, thereby allowing on to characterize wind variability in a way that is not possible with the instrumental record of surface pressure variations (AD 1884-present) (Visbeck, 2009). The second main result is that there may have been a weakening of the winds over the Southern Ocean could have been associated with the transition between the Medieval Climate Anomaly and the Little Ice Age. Change point analysis of tree ring $\Delta^{14} \mathrm{C}$ reveals that the interhemispheric gradient decreased by $2.2 \%$ about AD 1375, and this is consistent with a weakening of the winds over the Southern Ocean.

One should certainly exercise caution in using the results of the 20-yr sensitivity calculation in Fig. 6 to infer the magnitude of the centennial timescale changes evident in Fig. 1b about AD 1375. It is worth noting that changes in large-scale interhemispheric exchange time could also play a role in altering the interhemispheric gradient. However, a scaling argument for the impact of the interhemispheric exchange rate on the interhemispheric gradient supports our main contention that the Southern Ocean winds control the multi-decadal and longer timescale changes in the interhemispheric gradient shown in Fig. 1b. For modern conditions, 
the difference in the interhemispheric exchange timescale for tracers between extreme El Niño and La Niña years is 0.05-0.10 yr, according to the study of Lintner et al. (2004) using the NCEP MATCH (Model of Atmospheric Transport and Chemistry) model. The exchange timescale of this model is $0.86 \mathrm{yr}$, based on averages over the whole vertical column as opposed to surface concentrations as in Geller et al. (1997). Given the range of $0.05-0.10 \mathrm{yr}$, and dividing by the mean exchange time of $0.86 \mathrm{yr}$, one arrives at a net interhemispheric exchange time uncertainty of order 6$12 \%$. This scaling is justified as the analysis provided in the study of Lintner et al. (2004) applies generally to atmospheric gases. This would correspond to $\Delta^{14} \mathrm{C}$ gradient differences of $0.3-0.6 \%$, which is significantly less than the observed difference of $2.2 \%$ between the Medieval Climate Anomaly and the Little Ice Age. Indeed, changes in the interhemispheric exchange rate 4-8 times the size of those associated with ENSO would be required to explain this signal. A much more detailed and process-focused modeling study of this is currently underway, and will be the subject of a future publication. In pursuing this work, high-resolution coral records (Cobb et al., 2003; Druffel et al., 2007; Zaunbrecher et al., 2010) would provide potentially powerful constraints in understanding past changes in the physical state of the Equatorial Pacific Ocean.

Weakening of winds over the Southern Ocean during the Medieval Climate Anomaly to Little Ice Age transition is a new result that has not been previously presented in the climate literature. The question arises as to whether it is mechanistically linked with larger-scale changes in the global climate system. Here we return to the question raised at the end of the Introduction section, namely of whether Southern Ocean wind changes inferred from $\Delta^{14} \mathrm{C}$ are consistent with the atmospheric teleconnection mechanism that has been presented in the studies of Anderson et al. (2009) and Lee et al. (2011) to account for abrupt global climate change. There, abrupt cooling in the North Atlantic is associated with a southward shift in the mean position of the Intertropical Convergence Zone. In fact, this response would be fully consistent with the southward shift in the position of the Intertropical Convergence Zone inferred from paleo-proxy records in the study of Sachs et al. (2009) for the onset phase of the Little Ice Age. According to the mechanism of Anderson et al. (2009) and Lee et al. (2011), a southward excursion of the Intertropical Convergence Zone should be expected to drive an increase in the mean strength of the winds over the Southern Ocean in the Pacific sector.

At first glance, the sign (decrease) of the change of the amplitude of the strength of the Southern Ocean winds at the Medieval Climate Anomaly to Little Ice Age transition inferred from atmospheric $\Delta^{14} \mathrm{C}$ may be interpreted to be the opposite to what one would expect with the global atmospheric teleconnection mechanism proposed by Anderson et al. (2009) and then further developed by Lee et al. (2011). However, Lee et al. (2011) emphasized with their modeling
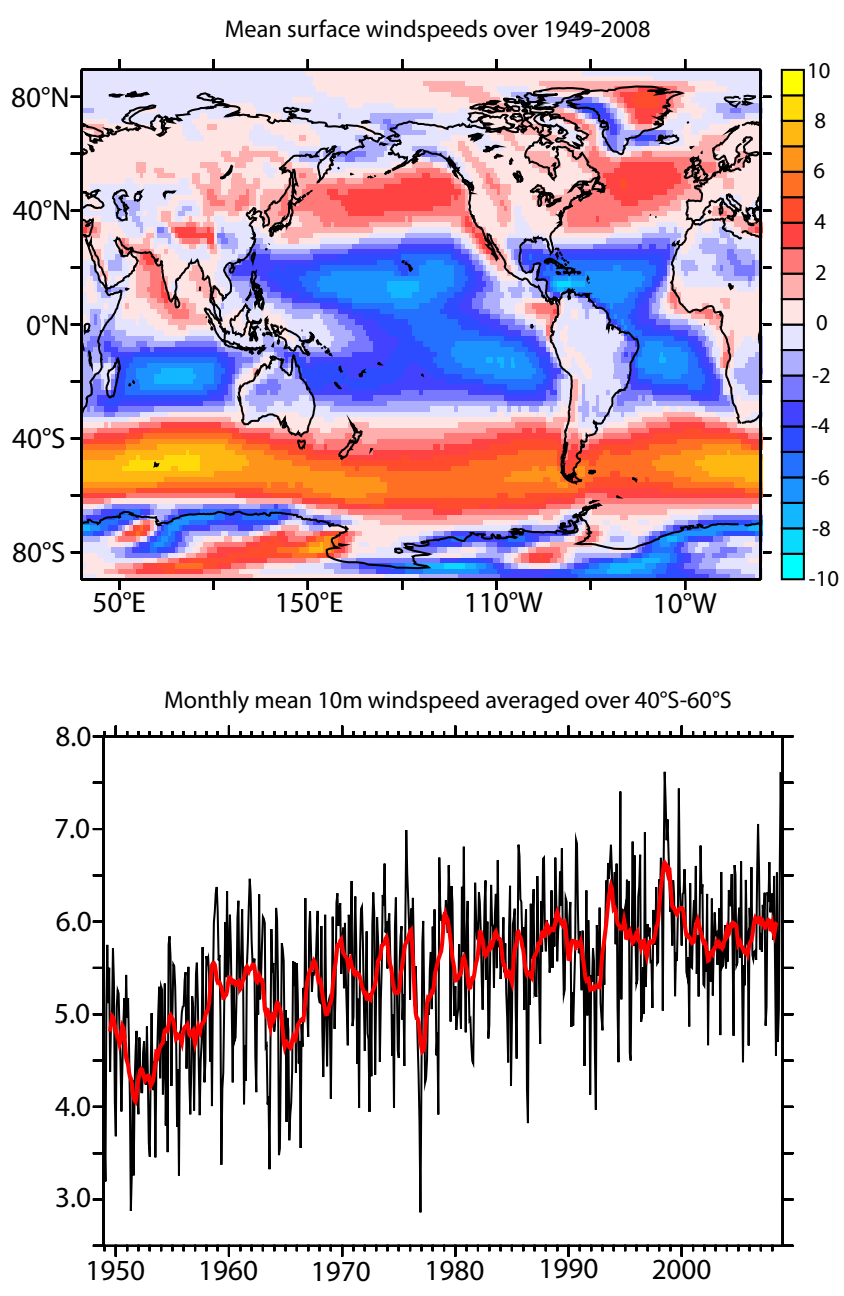

Fig. 7. NCEP (Kalnay et al., 1996) monthly mean $10 \mathrm{~m}$ windspeeds $\left[\mathrm{m} \mathrm{s}^{-1}\right]$. (a) Average over 1949-2008. (b) Timeseries over 19492008 of monthly mean values averaged over $40^{\circ} \mathrm{S}-60^{\circ} \mathrm{S}$.

results that they found a zonally asymmetric wind response over the Southern Ocean to Northern perturbations, with the Southern Ocean response being maximum over the Pacific sector. This stands in contrast to the perturbation we applied in this study, which was an axially symmetric scalar multiplication of wind strength. Thus it is plausible that the mechanism proposed by Anderson et al. (2009) and Lee et al. (2011) did drive an increase in winds over the South Pacific at the transition between the Medieval Warm Period and the Little Ice Age, but that this was more than compensated for in the drivers of atmospheric $\Delta^{14} \mathrm{C}$ by an independent mechanism acting over the other sectors of the Southern Ocean. A more systematic investigation of the mechanisms driving the changes inferred from Fig. $1 \mathrm{~b}$ is left as a subject for future investigation.

A role for the Southern Ocean in sustaining the mean interhemispheric gradient in atmospheric $\Delta^{14} \mathrm{C}$ was suggested in the earlier works of Braziunas et al. (1995), McCormac 
et al. (2002) and Levin and Hesshaimer (2000). All three of these studies invoked mean conditions over the Southern Ocean to account for the mean interhemispheric gradient in atmospheric $\Delta^{14} \mathrm{C}$. The current study differs from these earlier studies in two ways. First, our study is the first to provide an account of Southern Ocean mechanisms that can sustain the mean interhemispheric gradient in $\Delta^{14} \mathrm{C}$, as well as the time variability of this gradient. We have emphasized the value of the disequilibrium flux $\phi_{\text {diseq }}$ in understanding the interhemispheric gradient in $\Delta^{14} \mathrm{C}$, and demonstrated its connection to the large-scale overturning circulation of the ocean (Fig. 4). Second, whereas the focus of previous studies has been on the carbon cycle, we have chosen here to emphasize atmospheric $\Delta{ }^{14} \mathrm{C}$ as a dynamical tracer rather than as a tracer of the global carbon cycle. Nevertheless our main result, namely that natural decadal- to centennial-timescale variations in Southern Ocean winds may be expected to be large, should have important implications in the interpretation of records of variability in atmospheric $\mathrm{CO}_{2}$ concentrations as well. According to the model sensitivity in the study of Le Quéré et al. (2007), stronger winds should be associated with a net release of carbon from the ocean, and thereby drive the atmosphere towards higher atmospheric $\mathrm{CO}_{2}$ concentrations.

A comparison of Figs. $1 \mathrm{~b}$ and $5 \mathrm{a}$ revealed that there is a discrepancy between the simulated interhemispheric gradient in $\Delta^{14} \mathrm{C}$ and the gradient revealed in the tree ring data. The fact that the simulated gradient is weaker than the gradient revealed by tree ring records could derive from a number of sources. These include biases in: (1) the atmospheric model, (2) gas exchange, and (3) the oceanic model. For the atmospheric model, this could include biases in parameterizations of vertical transport and convection, the coarse resolution of the model, and biases in the climate state of the 1990s relative to the pre-anthropogenic period. As regards the ocean, in the next stage of our work we will use a higher-resolution ocean model that will include a biotic representation of the oceanic carbon cycle. There we will test the systematic uncertainty related to the choice of seaair flux parameterization (quadratic versus cubic) as well as ocean mixing parameter settings and choice of solar forcing fields. Regarding gas exchange, the implied natural variability in Southern Ocean winds inferred from Fig. 6 is approximately three times as large as the natural variability in Southern Ocean winds found in the coupled model of Galbraith et al. (2011), with the same being true for the higher resolution version of GFDL's CM2.1 coupled model (Delworth et al., 2006). This factor of $300 \%$ is much larger than the $11 \%$ $(25 \%-14 \%=11 \%)$ overestimate that we have used for the gas exchange coefficient.

An additional source of uncertainty in the atmosphere could result from a rectifying effect involving the stratospheric/tropospheric exchange in the two hemispheres. The previous study of Randerson et al. (2002) considered the seasonal cycle of this exchange for ${ }^{14} \mathrm{CO}_{2}$ in both hemi- spheres (their Fig. 3), and pointed out that the seasonality is significantly larger in the North. The maximum injection of ${ }^{14} \mathrm{CO}_{2}$ occurs in the northern spring, corresponding to the season or springtime tree growth. A simple scaling can provide an estimate of the impact on the mean interhemispheric gradient. First, we assume a simple two-box model for the troposphere, with the lateral boundary being at the equator, the upper boundary being the tropopause, and the lower boundary being the ocean surface. The ocean in the mean absorbs approximate $2.7 \mathrm{GtMCE}$ for the southern box and $0.9 \mathrm{GtMCE}$ in the northern box. If the flux across the top of the boxes is $1.8 \mathrm{GtMCE}$ in either hemisphere (following the calculations of Levin et al. (2009), according to which the differences are less than $10 \%$ in either hemisphere) then this implies an interhemispheric (southward) exchange of $0.9 \mathrm{GtMCE}$. If we assume that the amplitude of the flux from above into the Northern Hemisphere tropospheric box (1.8 GtMCE in the mean) has a seasonal amplitude of $0.9 \mathrm{GtMC} \mathrm{yr}^{-1}$, then the inventory variability is $0.9 \mathrm{GtMCE} /(2 \Pi)=0.14 \mathrm{GtMCE}=0.58 \%$ o. Including this rectifying effect would then increase the interhemispheric gradient by nearly $20 \%$.

Another potential source of uncertainty could be the parameterization of mesoscale eddies in the Southern Ocean. A number of studies (notably those of Straub, 1993; Hallberg and Gnanadesikan, 2006; Böning et al., 2008; Farneti et al., 2010) have argued that the type of non-eddying ocean model used here may exaggerate the dynamical response of the Southern Ocean to wind perturbations. However, the dominance of wind speed (which drives changes in gas exchange) over the influence of wind stress (which drives changes in upwelling) suggests that the variations in the interhemispheric gradient of $\Delta^{14} \mathrm{C}$ in Fig. $1 \mathrm{~b}$ stand as a robust result no matter what the eventual resolution of the role of ocean eddies may be. Given the strength of the winds over the Southern Ocean, this case would be stronger yet if a cubic wind speed-dependence for gas exchange (Wanninkhof and McGillis, 1999) turns out to be more accurate than the quadriatic formulation used here. Additionally, it is important to emphasize that the model configuration presented here has been used to test the sensitivity to the strength of the Southern Ocean winds, but not the latitude of the position of the maximum westerlies over the Southern Ocean. The type of perturbation chosen here finds justification in the results of d'Orgeville et al. (2010) who demonstrated for the case of $\mathrm{CO}_{2}$ that the sensitivity to wind strength is significantly stronger than the sensitivity to the longitude of the maximum westerlies.

Recent analysis of a coupled ocean-atmosphere model with steady solar and radiative forcing that includes $\Delta^{14} \mathrm{C}$ as a tracer in the ocean (Galbraith et al., 2011) gives results that are consistent with variability in the Southern Hemisphere dominating variability in the global sea-air exchange of ${ }^{14} \mathrm{CO}_{2}$. However, the unforced decadal-to-multidecadal variability of Southern Hemisphere westerlies exhibited by 
this coupled model is of much smaller magnitude than inferred from the analysis here. This opens up two interpretations for this discrepancy, either of which would have important implications. One possibility is that an external driver no included in the Galbraith et al. (2011) study, such as solar, volcanic or ice sheet variability, could be driving sizable variations in the Southern Hemisphere westerlies. A second possibility is that coupled climate models are significantly underestimating natural background variability in the Southern Ocean westerlies. We wish to underscore here that the second of these interpretations would be consistent with the hypothesis that we proposed in the Introduction for why the coupled earth system model in the study of Jungclaus et al. (2010) underestimates centennial variability in atmospheric $\mathrm{CO}_{2}$ concentrations over the last millenium.

We wish to reiterate that the model configuration presented here was by design intended to facilitate a series of process-perturbation sensitivity studies rather than simulations of past climate variability. The cost of spinning up radiocarbon as a tracer in a coupled climate model or earth system model is very high, due to an inherent equilibration timescale for oceanic radiocarbon of thousands of years. Due to simplifications inherent in the OCMIP-2 Abiotic formulation of $\Delta^{14} \mathrm{C}$, neither the ${ }^{14} \mathrm{CO}_{2}$ nor the $\mathrm{CO}_{2}$ simulated in the Atmospheric Transport Model can be used as research products by themselves. For this reason, we were not able to test or evaluate whether the mechanism emphasized here is appropriate to longer-timescale changes involving $\Delta^{14} \mathrm{C}$, or what the consequences of this mechanism are for changes in atmospheric $\mathrm{CO}_{2}$.

We have argued for a relatively simple link between the interhemispheric gradient and surface ocean fluxes of ${ }^{14} \mathrm{CO}_{2}$ and $\mathrm{CO}_{2}$, dominated by wind-driven changes over the Southern Ocean primarily through their impact on gas exchange. As such, the interhemispheric gradient in atmospheric $\Delta^{14} \mathrm{C}$ could serve as a powerful new proxy integrating the Southern westerly wind strength over large temporal and spatial scales. We note that the $\Delta^{14} \mathrm{C}$ gradient within the Southern Hemisphere is also significant (black line in Fig. 3) in addition to the overall interhemispheric gradient in $\Delta^{14} \mathrm{C}$. Thus documenting more precisely latitudinallyresolved $\Delta^{14} \mathrm{C}$ records may help to better constrain past changes in the diseqiulibrium flux $\phi_{\text {diseq }}$.

\section{Appendix A}

\section{$\Delta^{14} \mathrm{C}$ as a tracer}

Radiocarbon $\left({ }^{14} \mathrm{C}\right)$ is the radioactive isotope of carbon with a half-life of $5730 \mathrm{yr}$. Radiocarbon activities are usually reported as $\Delta{ }^{14} \mathrm{C}$. For practical purposes, this is the deviation in per mil units (parts per thousand) of the ratio ${ }^{14} \mathrm{C} /{ }^{12} \mathrm{C}$ from a decay-corrected isotopic standard (Stuiver and Polach, 1977), including a ${ }^{13} \mathrm{C}$-normalization for isotopic fractionation where, as an approximation, it has often been assumed that the fractionation is twice as large for ${ }^{14} \mathrm{C}$ as for ${ }^{13} \mathrm{C}$. A precise definition of $\Delta{ }^{14} \mathrm{C}$ has been presented in the study of Stuiver and Polach (1977):

$$
\begin{aligned}
\Delta^{14} \mathrm{C}=1000 . & \cdot\left\{\left[\left(1+\left(\delta^{14} \mathrm{C} / 1000\right)\right) \cdot\left((0.975)^{2}\right)\right.\right. \\
\cdot & \left.\left(\left(1+\left(\delta^{13} \mathrm{C} / 1000 .\right)^{-2}\right)\right]-1.0\right\}
\end{aligned}
$$

where $\delta^{14} \mathrm{C}$ is defined as the relative difference between the absolute international standard activity $\left(A_{\text {abs }}\right)$ and sample activity $\left(A_{\mathrm{s}}\right)$ that has been corrected for the age of the sample, but has not been corrected for $\delta^{13} \mathrm{C}$ :

$\left.\delta^{14} \mathrm{C}=\left\{\left(A_{\mathrm{S}} e^{\lambda(y-x)} / A_{\mathrm{abs}}\right)-1\right)\right\} \cdot 1000$ per mil

for the case of a tree ring grown in year $x$ and measured in year $y$, and $\lambda$ represents the $5730 \mathrm{yr}$ half-life of ${ }^{14} \mathrm{C}$ $\left(\lambda=1 / 8267 \mathrm{yr}^{-1}\right)$. Similarly:

$\delta^{13} \mathrm{C}=\left(R_{\mathrm{S}} / R_{\mathrm{PDB}}-1\right) \cdot 1000$

with $R_{\mathrm{S}}$ and $R_{\mathrm{PDB}}$ being the ${ }^{13} \mathrm{C} /{ }^{12} \mathrm{C}$ ratios of sample and a standard, respectively. The first of the above equations is commonly simplified to:

$$
\Delta^{14} \mathrm{C}=\delta^{14} \mathrm{C}-2 \cdot\left(\delta^{13} \mathrm{C}+25\right)\left(1+\left(\delta^{14} \mathrm{C} / 1000 .\right)\right)
$$

For the analysis considered here, the $\Delta^{14} \mathrm{C}$ tracer is simplified by neglecting ${ }^{13} \mathrm{C}$ :

$\Delta{ }^{14} \mathrm{C}=\left(\left({ }^{14} \mathrm{C} /{ }^{12} \mathrm{C}\right) \cdot \mathrm{r}^{12 / 14}-1\right) \cdot 1000$

Here $\mathrm{r}^{12 / 14}$ is the pre-anthropogenic ratio of ${ }^{12} \mathrm{C}$ to ${ }^{14} \mathrm{C}$ in the atmosphere. As long as one assumes that $\delta^{13} \mathrm{C}$ is not affected by wind-driven changes in ocean dynamics and gas exchange, the variability of atmospheric $\Delta^{14} \mathrm{C}$ can be identified approximately with changes in the ${ }^{14} \mathrm{C}$-to- ${ }^{12} \mathrm{C}$ ratio in the model atmosphere.

The zero level for $\Delta^{14} \mathrm{C}$ is chosen to correspond to the $\Delta^{14} \mathrm{C}$ of the absolute radiocarbon standard, which is 1890 wood (Broecker and Olson, 1959). For the preanthropogenic climate system, one usually assumes a "mean state" with $\Delta^{14} \mathrm{C}=0 \%$ in the atmosphere where decay is balanced by production of ${ }^{14} \mathrm{C}$ in the upper atmosphere through the effect of cosmic rays (spallation). It is thought that spallation produces equal amounts of ${ }^{14} \mathrm{C}$ in either hemisphere, with the transport of ${ }^{14} \mathrm{C}$ between the stratosphere and the troposphere occurring nearly completely in the hemisphere where ${ }^{14} \mathrm{C}$ was produced. The sum of the spallationproduction in the atmosphere is balanced by the decay of $\mathrm{DI}^{14} \mathrm{C}$ in the ocean interior, and to a lesser degree in the atmosphere and the terrestrial biosphere, via radioactive decay. For this pre-anthropogenic state, scaling arguments indicate that the net radiocarbon fluxes into the terrestrial biosphere were relatively small, as described in Sect. $2 b$. The variations of $\Delta^{14} \mathrm{C}$ shown in Fig. 1 are thought of as being small perturbations about this steady state. 
The atmospheric $\Delta^{14} \mathrm{C}$ values used in the study are taken from the IntCal04 (Reimer et al., 2004) and SHCal04 (McCormac et al., 2004) data sets. The IntCal04 data set is based on single year radiocarbon analyses of tree-rings from the US Pacific coast for the period AD 1510-1950 and 10-yr blocks of tree-ring measurements for the entire period from both US and British Isle trees as described in Reimer et al. (2004). The data were combined using a random walk model (Buck and Blackwell, 2004) and evaluated at 5-yr resolution. The SHCal04 dataset was similarly modeled from single or multiple blocks of tree-ring radiocarbon analyses from Chilean wood for the period AD 1665-1950 and 10-yr blocks of treerings from New Zealand and South Africa (Hogg et al., 2002; McCormac et al., 2004).

\section{Appendix B}

\section{Monte Carlo simulations for change point tests}

In order to independently test the hypothesis that there is a shift in the interhemispheric gradient associated with the Medieval Climate Anomaly and the Little Ice Age, we apply the change point test developed by Worsley (1979) to the time series for $\Delta^{14} \mathrm{C}$ in Fig. 1b over AD 950-1830. This approach allows one to test whether a shift in the mean occurs, and in the latter case to determine when it occurs. A significant shift in the mean (>99\% confidence level) was detected in 1375 , with the mean before the change being $-6.63 \%$ and the mean after the change being $-4.48 \%$. To verify that the variance remains constant in time, we applied the test for a shift in variance developed by Inclan and Tiao (1994) and found (at the $95 \%$ confidence level) that the variance does not seem to change over the interval 950-1830. The analysis was repeated for the time interval AD 950-1860 (instead of 950-1830) and the same transition in AD 1375 was identified. Thus, this result is not sensitive to whether one includes growth in ${ }^{14} \mathrm{CO}_{2}$-depleted fossil fuels over the period 1830-1860.

In the parlance of climate science, the time series contains red noise. Due to the presence of red noise in the time series, the confidence levels presented above were obtained through Monte Carlo simulations with a similar methodology as used by Wang (2008). Hence, the techniques developed by Worsley (1979) and Inclan and Tiao (1994) were designed for independent (no correlation in time) and identically distributed normal errors. When these conditions do not apply, the distributions of the statistical tests of Worsley (1979) can be affected, and thus the percentiles derived under the assumption of independence and identically distributed normal errors are inappropriate. We were cautious about this point in the analysis presented here. For this reason, we used Monte Carlo simulations to obtain the critical values of these two statistics under a red noise model. We consider the red noise model in the residuals after subtracting the means to avoid a shift in the mean to interfere with the estimation of the parameters of the model. We identified that the residuals can be represented by a second order autocorrelation model $(\mathrm{AR}(2))$ which can be expressed as:

$x_{i}=1.02 x_{i-1}-0.25 x_{i-2}+e_{i}$

where $x_{i}$ designates the $\Delta^{14} \mathrm{C}$ at time $t$ and $e_{i}$ is the white noise residual. Using this model, we generated 10000 time series of random numbers from a normal distribution having the same red noise characteristics (length, white noise variance and autocorrelation parameters) as observed in the $\Delta^{14} \mathrm{C}$ residuals. These two change point statistics were computed in all synthetic series and the critical values of the two change point statistics were obtained. These new critical values were used to test for a shift in the mean and in the variance of Sect. 1, instead of the original critical values presented in Worsley (1979) and Inclan and Tiao (1994), which were obtained under the independence assumption.

Acknowledgements. We would first like to thank the Associate Editor (Christine Hatté) for her careful attention to the manuscript. Her numerous comments and suggestions greatly strengthened the presentation and interpretation. We would also like to thank the three anonymous reviewers for their insightful comments and suggestions. Additionally, we would like to thank John Chiang at U. C. Berkeley for numerous discussions about climate dynamical mechanisms that may have driven variability over the last millennium. This report was prepared by K. B. R. under awards NA17RJ2612 and NA08OAR4320752, which includes support through the NOAA Office of Oceanic and Atmospheric Research (OAR) through the Office of Climate Observations (OCO). We wish to thank DOE for their support through DE-FG02-07ER64467, NOAA for their CPT support through NOAA NA07OAR4310096, and both BP and the Ford Motor Company for support through the Carbon Mitigation Initiative (CMI) at Princeton University. Support for S. E. Mikaloff-Fletcher comes from the New Zealand Foundation for Research, Science and Technology, contract number C01X0703, as well as ESRL funding through NOAA/CICS award NA08OAR4320752. Support for C. B. came through Fonds Québécois de la Recherche sur la Nature et les technologies in addition to the CMI.

Edited by: C. Hatté

\section{References}

Anderson, A. F., Ali, S., Bradtmiller, L. I., Nielsen, S. H. H., Fleisher, M. Q., Anderson, B. E., and Burckle, L. H.: Wind-driven upwelling in the Southern Ocean and the deglacial rise in atmospheric $\mathrm{CO}_{2}$, Science, 323, 1443, doi:10.1126/science.1167441, 2009.

Aumont, O.: Étude du cycle naturel du carbone dans un modèle 3-D de l'océan mondial, PhD. Thesis, Univ. Paris VI, Paris, 1998.

Battle, M., Mialoff-Fletcher, S., Bender, M. L., Keeling, R. F., Manning, A. C., Gruber, N., Tans, P. P., Hendricks, M. B., Ho, D. T., Simonds, C., Mika, R., and Paplawsky, B.: Atmospheric potential oxygen: New observations and their implications for some 
atmospheric and oceanic models, Global Biogeochem. Cy., 20, GB1010, doi:10.1029/2005GB002534, 2006.

Böning, C., Dispert, A., Visbeck, M., Rintoul, S., and Scharzkopf, F.: The response of the Antarctic Circumpolar Current to recent climate change, Nat. Geosci., 1, 864-869, 2008.

Braziunas, T. F., Fung, I. Y., and Stuiver, M.: The preindustrial atmospheric ${ }^{14} \mathrm{CO}_{2}$ latitudinal gradient as related to exchanges among atmospheric, oceanic, and terrestrial reservoirs, Global Biogeochem. Cy., 9, 565-584, 1995.

Broecker, W. S. and Olson, E. A.: Lamont Radiocarbon Measurements VI, Radiocarbon, 1, 111-132, 1959.

Buck, E. and Blackwell, P. G.: Formal statistical models for estimating radiocarbon calibration curves, Radiocarbon, 46, 1093-1102, 2004.

Cobb, K. M., Charles, C. D., Edwards, R. L., Cheng, H., and Kastner, M.: El Niño-Southern Oscillation and tropical Pacific climate during the last millennium, Nature, 242, 271-276, 2003.

da Silva, A., Young, A. C., and Levitus, S.: Atlas of Surface marine Data 1994, Vol. 1, Algorithms and Procedures, NOAA Atlas NESDIS 6, Natl. Oceanic and Atmos. Admin., Silver Spring, Md, 1994.

Delworth, T. L, Broccoli, A. J., Rosati, A., Stouffer, R. J., Balaji, V., Beesley, J. A., Cooke, W. F., Dixon, K. W., Dunne, J., Dunne, K. A., Durachta, J. W., Findell, K. L., Ginoux, P., Gnanadesikan, A., Gordon, C. T., Griffies, S. M., Gudgel, R., Harrison, M. J., Held, I. M., Hemler, R. S., Horowitz, L. W., Klein, S. A., Knutson, T. R., Kushner, P. J., Langenhorst, A. R., Lee, H.-C., Lin, S.-J., Lu, J., Malyshev, S. L., Milly, P. C. D., Ramaswamy, V., Russell, J., Daniel Schwarzkopf, M., Shevliakova, E., Sirutis, J. J., Spelman, M. J., Stern, W. F., Winton, M., Wittenberg, A. T., Wyman, B., Zeng, F., and Zhang, R.: GFDL's CM2 GLobal Coupled Climate Models, Part I: Formulation and Simulation Characteristics, J. Climate, 19, 643-674, 2006.

d'Orgeville, M., Sijp, W. P., England, M. H., and Meissner, K. J.: On the control of glacial-interglacial atmospheric $\mathrm{CO}_{2}$ variations by the Southern Hemisphere westerlies, Geophys. Res. Lett., 37 , L21703, doi:10.1029/2010GL045261, 2010.

Druffel, E. R. M., Griffin, S., Beaupre, S. R., and Dunbary, R. B.: Oceanic climate and circulation changes during the past four centuries from radiocarbon in corals, Geophys. Res. Lett., 34, L09601, doi:10.1029/2006GL028681, 2007.

Etheridge, D., Steele, L., Langenfelds, R., Francey, R., Barnola, J., and Morgan, V.: Natural and anthropogenic chnages in atmospheric $\mathrm{CO}_{2}$ over the last 1000 years from air in Antarctic ice and firn, J. Geophys. Res., 101, 4115-4128, 1996.

Farneti, R., Delworth, T. I., Rosati, A. J., Griffies, S. M., and Zhang, F.: The role of mesoscale eddies in the rectification of the Southern Ocean response to climate change, J. Phys. Oceaonogr., 40, 1539-1557, 2010.

Feely, R. A., Wanninkhof, R., Takahashi, T, and Tans, P.: Influence of El Nino on the equatorial Pacific contribution to atmospheric $\mathrm{CO}_{2}$ accumulation, Nature, 398, 597-601, 1999.

Galbraith, E. D., Kwon, E. Y., Gnanadesikan, A., Rodgers, K. B., Griffies, S. M., Bianchi, D., Sarmiento, J. L., Dunne, J. P., Simeon, J., Slater, R. D., Wittenberg, A. T., and Held, I. M.: The Impact of Climate Variability on the Distribution of Radiocarbon in CM2Mc, a New Earth System Model, J. Climate, 24, 42304254, doi:10.1175/2011JCLI3919.1.

Geller, L. S., Elkins, J. W., Lobert, J. M., Clarke, A. D., Hurst, D.
F., Butler, J. H., and Myers, R. C.: Tropospheric $\mathrm{SF}_{6}$ : Observed latitudinal distribution and trends, derived emissions and interhemispheric exchange time, Geophys. Res. Lett., 24, 675-678, 1997.

Gnanadesikan, A., Slater, R. D., Gruber, N., and Sarmiento, J. L.: Ocean vertical exchange and new production: a comparison between models and observations, Deep-Sea Res. II, 49, 363-401, 2002.

Gnanadesikan, A., Dunne, J. P., Key, R. M., Matsumoto, K., Sarmiento, J. L., Slater, R. D., and Swathi, P. S.: Ocean ventilation and biogeochemical cycling: Understanding the physical mechanisms that produce realistic distributions of tracers and productivity, Global Biogeochem. Cy., 18, BG4010, doi:10.1029/2003GB002087, 2004.

Gurney, K., Law, R., Rayner, P., and Denning, A. S.: TransCom 3 Experimental Protocol, Department of Atmospheric Sciences, Colorado State University, USA, Paper No. 707, 2000.

Hallberg, R. and Gnanadesikan, A.: The role of eddies in determining the structure and response of the wind-drive Southern Hemisphere overturning: Results from the Modeling Eddies in the Southern Ocean (MESO) project, J. Phys. Oceanogr., 36, 2232 2252, 2006.

Heimann, M. and Körner, S.: The global atmospheric tracer model TM3, in Max-Planck-Institut für Biogeochemie (Eds.): Technical Resport, Vol. 5, Max-Planck-Institut für Biogeochemie, Jena, 131 Pp., [BGC0601; ECO140/036+5], 2003.

Hogg, A. G., McCormac, F. G., Higham, T. F. G., Reimer, P. J., Baillie, M. G. L., and Palmer, J. G.: High-precision radiocarbon measurements of contemporaneous tree-ring dated wood from the British Isles and New Zealand: AD 1850-950, Radiocarbon, 44, 633-650, 2002.

Inclan, C. and Tiao, G.: Use of cumulative sums of squares for retrospective detection of changes in variance, J. Am. Stat. Assoc., 89, 913-923, 1994.

Jungclaus, J. H., Lorenz, S. J., Timmreck, C., Reick, C. H., Brovkin, V., Six, K., Segschneider, J., Giorgetta, M. A., Crowley, T. J., Pongratz, J., Krivova, N. A., Vieira, L. E., Solanki, S. K., Klocke, D., Botzet, M., Esch, M., Gayler, V., Haak, H., Raddatz, T. J., Roeckner, E., Schnur, R., Widmann, H., Claussen, M., Stevens, B., and Marotzke, J.: Climate and carbon-cycle variability over the last millennium, Clim. Past, 6, 723-737, doi:10.5194/cp-6723-2010, 2010.

Kalnay, E. C., Kanamitsu, M., Kistler, R., Collins, W., Deaven, D., Gandin, L., Iredell, M., Saha, S., White, G., Woollen, J., Zhu, Y., Chellian, M., Ebisuzaki, W., Higgins, W., Janowiak, J., Mo, K. C., Ropelewski, C., Wang, J., Leetmaa, A., Reynolds, R., Jenne, R., and Joseph, D.: The NCEP/NCAR reanalysis project, B. Am. Meteorol. Soc., 77, 347-471, 1996.

Key, R. M., Kozyr, A., Sabine, C. L., Lee, K., Wanninkhof, R., Bullister, J. L., Feely, R. A., Millero, F. J., Mordy, C., and Peng, T.-H.: A global ocean carbon climatology: Results from Global Data Analysis Project (GLODAP), Global Biogeochem. Cy., 18, BG4031, doi:10.1029/2004GB002247, 2004.

Krakauer, N. Y., Randerson, J. T., Primeau, F. W., Gruber, N., and Menemenlis, D.: Carbon isotope evidence for the latitudinal distribution and wind speed dependence of the air-sea gas transfer velocity, Tellus, 58B, 390-417, 2006.

Lee, S.-Y., Chiang, J. C. H., Matsumoto, K., and Tokos, K. S.: Southern Ocean wind response to North Atlantic cooling and 
the rise in atmospheric $\mathrm{CO}_{2}$ : Modeling perspective and paleoceanographic implications, Paleoceanography, 27, PA1214, doi:10.1029/2010PA002004, 2011.

Le Quéré, C., Orr, J. C., Monfray, P., and Aumont, O.: Interannual variability of the oceanic sink of $\mathrm{CO}_{2}$ from 1979 through 1997 , Global Biogeochem. Cy., 14, 1247-1265, 2000.

Le Quéré, C., Rödenbeck, C., Buitenhuis, E. T., Conway, T. J., Langenfelds, R., Gomez, A., Labuschagne, C., Ramonet, M., Nakazawa, T., Metzl, N., Gillett, N., and Heimann, M.: Saturation of the Southern Ocean $\mathrm{CO}_{2}$ sink due to recent climate change, Science, 316, 1735-1738, 2007.

Levin, I. and Hesshaimer, V.: Radiocarbon - A Unique Tracer of Global Carbon Cycle Dynamics, Radiocarbon, 42, 69-80, 2000.

Levin, I., Naegler, T., Kromer, B., Diehl, M., Francey, R. J., GomezPelaez, A. J., Steele, L. P., Wagenbach, D., Weller, R., and Worthy, D. E.: Observations and modelling of the global distribution and long-term trend of atmospheric ${ }^{14} \mathrm{CO}_{2}$, Tellus B, 62, 26-46, 2009.

Lintner, B. R., Gilliland, A. B., and Fung, I. Y.: Mechanisms of convection-induced modulation of passive tracer interhemispheric transport interannual variability, J. Geophys. Res, 109, D13102, doi:10.1029/2003JD004306, 2004.

Masarik, J. and Beer, J.: Simulation of particle fluxes and cosmogenic radionuclide formation in Earth's atmosphere, J. Geophys. Res., 104, 12099-13012, 1999.

McCormac, F. G., Reimer, P. J., Hogg, A. G., Higham, T. F. G., Baillie, M. G. L., Palmer, J., and Stuiver, M.: Calibration of the radiocarbon time scale for the Southern Hemisphere: AD 1850950, Radiocarbon, 44, 641-651, 2002.

McCormac, F. G., Hogg, A. G., Blackwell, P. G., Buck, C. E., Higham, T. F. G., and Reimer, P. J.: SHCAL04 Southern Hemisphere Calibration, 0-11 cal kyr BP, Radiocarbon, 46, 10871092, 2004.

Mignone, B. K., Gnanadesikan, A., Sarmiento, J. L., and Slater, R. D.: Central Role of Southern Hemisphere winds and eddies in modulating the oceanic uptake of anthropogenic carbon, Geophys. Res. Lett., 33, L01604, doi:10.1029/2005GL024464, 2006.

Naegler, T.: Reconciliation of excess ${ }^{14} \mathrm{C}$-based global $\mathrm{CO}_{2}$ piston velocity estimates, Tellus, 61B, 372-384, doi:10.1111/j.16000889.2008.00408.x, 2009.

Naegler, T., Ciais, P., Rodgers, K., and Levin, I.: Excess radiocarbon constraints on air-sea gas exchange and the uptake of $\mathrm{CO}_{2}$ by the oceans, Geophys. Res. Lett., 33, L11802, doi:10.1029/2005GL025408, 2006.

Naegler, T., Ciais, P., Orr, J. C., Aumont, O., and Rödenbeck, C.: On evaluating ocean models with atmospheric potential oxygen, Tellus, 69B, 138-156, 2007.

Obata, A. and Kitamura, Y.: Interannual variability of the sea-air exchange of $\mathrm{CO}_{2}$ from 1961 to 1998 simulated with a global ocean circulation-biogeochemistry model, J. Geophys. Res., 108, 3337, doi:10.1029/2001JC001088, 2003.

Pacanowski, R. C. and Griffies, S. M.: The MOM3 manual, alpha version, NOAA/Geophys, Fluid Dyn. Lab., Princeton, N. J., 1999.

Randerson, J. T., Thompson, M. V., Conway, T. J., Fung, I. Y., and Field, C. B.: The contribution of terrestrial sources and sinks to trends in the seasonal cycle of atmospheric carbon dioxide, Global Biogeochem. Cy., 11, 535-560, 1997.

Randerson, J. T., Enting, I. G., Schnurl, A. A. G., Caldeira, K., and
Fung, I. Y.: Seasonal and latituindal variability of troposphere $\Delta^{14} \mathrm{CO}_{2}$ : Post bomb contributions from fossil fuels, oceans, the stratosphere, and the terrestrial biosophere, Global Biogeochem. Cy., 16, 1112, doi:10.1029/2002GB001876, 2002.

Reimer, P. J., Baillie, M. G. L., Bard, E., Bayliss, A., Beck, J. W., Bertrand, C. J. H., Blackwell, P. G., Buck, C. E., Burr, G. S., Cutler, K. B., Damon, P. E., Edwards, R. L., Fairbanks, R. G., Friedrich, M., Guilderson, T. P., Hott, A. G., Hughen, K. A., Kromer, B., McCormac, G., Manning, S., Ramsey, C. B., Reimer, R. W., Remmele, S., Southon, S. R., Stuiver, M., Talamo, S., Taylor, F. W., van der Plicht, J., and Weyhenmeyer, C. E.: INTCAL Terrestrial Radiocarbon Age Calibration, 0-26, Cal kyr AP, Radiocarbon, 46, 1029-1058, 2004.

Rödenbeck, C., Le Quéré, C., Heimann, M., and Keeling, R. F.: Interannual variability in oceanic biogeochemical processes inferred by inversion of atmospheric $\mathrm{O}_{2} / \mathrm{N}_{2}$ and $\mathrm{CO}_{2}$ data, Tellus, Ser. B., 60, 685-705, 2008.

Rubin, S. and Key, R. M.: Separating natural and bombproduced radiocarbon in the ocean: The potential alkalinity method, Global Biogeochem. Cy., 16, 1105, doi:10.1029/2001GB001432, 2002.

Sachs, J. P., Sachse, D., Smittenberg, R. H., Zhang, Z., Battisti, D. S., and Golubic, S.: Southward movement of the Pacific intertropical convergence zone AD 1400-1850, Nat. Geosci., 2, 519-525, 2009.

Sigenthaler, U.: Carbon Dioxide: Its natural cycle and anthropogenic perturbation, in: The role of air-sea gas exchange in geochemical cycling, edited by: Buat-Ménard, P., 209-247, D. Reidel, Dordecht, 1986.

Siegenthaler, U., Heimann, M., and Oeschger, H.: ${ }^{14} \mathrm{C}$ Variations caused by changes in the global carbon cycle, Radiocarbon, 22, 177-191, 1980.

Straub, D. N.: On the transport and angular momentum balance of channel models of the Antarctic Circumpolar Current, J. Phys. Oceanogr., 23, 776-782, 1993.

Stuiver, M. and Polach, H. A.: Discussion reporting of ${ }^{14} \mathrm{C}$ data, Radioarbon, 19, 355-363, 1977.

Stuiver, M. and Quay, P. D.: Changes in Atmospheric Carbon14 attributed to a variable sun, Science, 207, 4426, 11-19, doi:10.1126/science.207.4426.11, 1980.

Sweeney, C., Gloor, E., Jacobson, A. R., Key, R. M., McKinlye, G., Sarmiento, J. L., and Wanninkhof, R.: Constraining air-sea gas exchange for $\mathrm{CO}_{2}$ with recent bomb ${ }^{14} \mathrm{C}$ measurements, Global Biogeochem. Cy., 21, GB2015, doi:10.1029/2006GB002784, 2007.

Toggweiler, J. R., Dixon, K., and Broecker, W. S.: The Peru upwelling and the ventilation of the South Pacific thermocline, J. Geophys. Res., 96, 20467-20497, 1991.

Trenberth, K. E., Olsen, J. G., and Large, W. G.: A global ocean wind stress climatology based on ECMWF analyses, Tech Rep. NCAR/TN-335+STR, Natl. Cent. For Atmos. Res., Boulder, Colo., 1989.

Turnbull, J. C., Miller, J. B., Lehman, S. J., Hurst, D., Peters, W., Tans, P. P., Southon, J., Montzka, S. A., Elkins, J. W., Mondeel, D. J., Romashkin, P. A., Elansky, N., and Skorokhod, A.: Spatial distribution of $\Delta^{14} \mathrm{CO}_{2}$ across Eurasia: measurements from the TROICA-8 expedition, Atmos. Chem. Phys., 9, 175187, doi:10.5194/acp-9-175-2009, 2009.

Turney, C. S. M. and Palmer, J.: Does the El Niño-Southern Oscilla- 
tion control the interhemispheric radiocarbon offset?, Quaternary Res., 67, 174-180, 2007.

Visbeck, M.: A station-based Southern Annular Mode Index from 1884 to 2005, J. Climate, 22, 940-950, 2009.

Wang, X. L.: Accounting for autocorrelation in detecting mean shifts in climate data series, using the penalized maximum $t$ or F test, J. Appl. Meteorol. Clim., 47, 2423-2444, 2008.

Wanninkhof, R.: Relationship between gas exchange and wind speed over the ocean, J. Geophys. Res., 97, 7373-7381, 1992.

Wanninkhof, R. and McGillis, W. R.: A cubic relationship between air-sea $\mathrm{CO}_{2}$ exchange and windspeed, Geophys. Res. Lett., 26, 1889-1892, 1999.
Worsley, K. J.: On the likelihood ratio test for a shift in location of normal populations, J. Am. Stat. Assoc., 74, 365-367, 1979.

Wunsch, C.: Towards understanding the Paleocean, Quaternary Sci. Rev., 29, 1960-1967, 2010.

Zaunbrecher, L. K., Cobb, K. M., Beck, J. W., Charles, C. D., Druffel, E. R. M., Fairbanks, R. G., Griffin, S., and Sayani, H. R.: Coral records of central tropical Pacific radiocarbon variability during the last millennium, Paleoceanography, 25, PA4212, doi:10.1029/2009PA001788, 2010. 